\title{
VDAC1 at the crossroads of cell metabolism, apoptosis and cell stress
}

\author{
Varda Shoshan-Barmatz ${ }^{1, *}$, Eduardo N. Maldonado ${ }^{2}$ and Yakov Krelin ${ }^{1}$ \\ ${ }^{1}$ Department of Life Sciences and the National Institute for Biotechnology in the Negev, Ben-Gurion University of the Negev, Beer- \\ Sheva, 84105, Israel. \\ ${ }^{2}$ Department of Drug Discovery \& Biomedical Sciences, Medical University of South Carolina, Charleston, SC, USA. \\ * Corresponding Author: \\ Prof. Varda Shoshan-Barmatz, Department of Life Sciences, Ben-Gurion University of the Negev, Beer-Sheva 84105, Israel; Fax : $972-$ \\ 8-647 2992; E-mail: vardasb@bgu.ac.il
}

ABSTRACT This review presents current knowledge related to VDAC1 as a multi-functional mitochondrial protein acting on both sides of the coin, regulating cell life and death, and highlighting these functions in relation to disease. It is now recognized that VDAC1 plays a crucial role in regulating the metabolic and energetic functions of mitochondria. The location of VDAC1 at the outer mitochondrial membrane (OMM) allows the control of metabolic cross-talk between mitochondria and the rest of the cell and also enables interaction of VDAC1 with proteins involved in metabolic and survival pathways. Along with regulating cellular energy production and metabolism, VDAC1 is also involved in the process of mitochondria-mediated apoptosis by mediating the release of apoptotic proteins and interacting with antiapoptotic proteins. VDAC1 functions in the release of apoptotic proteins located in the mitochondrial intermembrane space via oligomerization to form a large channel that allows passage of cytochrome $c$ and AIF and their release to the cytosol, subsequently resulting in apoptotic cell death. VDAC1 also regulates apoptosis via interactions with apoptosis regulatory proteins, such as hexokinase, $\mathrm{Bcl} 2$ and $\mathrm{Bcl}-\mathrm{xL}$, some of which are also highly expressed in many cancers. This review also provides insight into VDAC1 function in $\mathrm{Ca}^{2+}$ homeostasis, oxidative stress, and presents VDAC1 as a hub protein interacting with over $\mathbf{1 0 0}$ proteins. Such interactions enable VDAC1 to mediate and regulate the integration of mitochondrial functions with cellular activities. VDAC1 can thus be considered as standing at the crossroads between mitochondrial metabolite transport and apoptosis and hence represents an emerging cancer drug target. doi: $10.15698 /$ cst2017.10.104 Received originally: 05.06.2017; in revised form: 21.09.2017, Accepted 22.09.2017, Published 01.10.2017.

Keywords: apoptosis, cancer, metabolism, mitochondria, VDAC1.
Abbreviations:
AB-Amyloid beta
$A D$-Alzheimer's disease
ALS - amyotrophic lateral sclerosis,
AIF - apoptosis-inducing factor
$A N T$ - adenine nucleotide translocase,
BCl-2 - B-cell lymphoma 2,
CSC - cancer stem cell,
$C V D$ - cardiovascular disease,
Cyto c - cytochrome c,
DIDS - 4,4-diisothiocyanostilbene-2,2-
disulfonic acid,
HK-hexokinase,
IMM - inner mitochondrial membrane
IMS - intermembrane space,
NSCLC - non-small cell lung cancer
miRNA - micro RNA
$O M M$ - outer mitochondrial
membrane
OXPHOS-oxidative phosphorylation,
PTP - permeability transition pore,
RNAi - RNA interference,
$R O S$ - reactive oxygen species,
TSPO - translocator protein,
T2D - type 2 diabetes,
VDAC - voltage-dependent anion
channel.

\section{VDAC ISOFORMS, STRUCTURE, AND CHANNEL ACTIVI-}

TY

VDAC isoforms and cellular localization

Three different VDAC isoforms, VDAC1, VDAC2 and VDAC3, sharing $~ 70 \%$ identity and structural and some functional properties [1, 2], are expressed in mammalian mitochondria, with VDAC1 being the major protein expressed. However, significantly differences in the functions of the three isoforms were found $[1,3,4]$, suggesting they assume different physiological roles $[1,5]$. The three isoforms are 
expressed in most tissue types, with VDAC1 expression being higher than that of VDAC2 and VDAC3 in most but not all tissues $[1,2]$.

Both VDAC1- and VDAC3-deficient mice are viable. However, VDAC1 ${ }^{-1-}$ mice (inbred $\mathrm{C} 57 \mathrm{BL} / 6$ background) were born in less than expected numbers according to the Mendelian ratio, suggesting partial embryonic lethality. Studies using $V D A C 1^{-/}$mice confirmed the importance of this protein as a carrier of metabolites across the OMM [6]. In mice, deletion of VDAC1 and VDAC2 reduces respiratory capacity [7], and the absence of VDAC3 causes male sterility, while a lack of both VDAC1 and VDAC3 causes growth retardation [8] and is associated with deficits in learning behavior and synaptic plasticity [9]. In this review, the focus will be on the VDAC1 isoform.

Using various approaches, VDAC was detected not only in the mitochondria but also in other cell compartments [3], such as the plasma membrane $[3,10]$, including the caveolae and caveolae-like domains [11], the sarcoplasmic reticulum (SR) of skeletal muscles [12], and the ER of rat cerebellum $[13,14]$. A possible mechanism for targeting VDAC protein to the plasma membrane proposes that this version of the protein contains an $\mathrm{N}$-terminal signal peptide responsible for targeting to the cell membrane $[15,16]$. The exact function of extra-mitochondrial VDAC is unknown, although several possible roles have been proposed (reviewed in [17]).

\section{VDAC1 structure, channel conductance, properties and regulation}

The three-dimensional structure of VDAC isoform 1 was determined at atomic resolution, revealing that VDAC1 is composed of 19 transmembrane $\beta$-strands connected by flexible loops to form a $\beta$-barrel, with strands $\beta 1$ and $\beta 19$ being in parallel conformation along with a 25 -residue-long $\mathrm{N}$-terminal region that lies inside the pore [18-20] (Fig.1A). The $\mathrm{N}$-terminal region is proposed to move in the open space [21] and translocate from the internal pore to the channel surface [22] (Fig.1B). This segment is ideally positioned to regulate the conductance of ions and metabolites passing through the VDAC1 pore $[20,18]$.

The pore diameter of the channel has been estimated to be between 3 and $3.8 \mathrm{~nm}$ [18], and is decreased to about $1.5 \mathrm{~nm}$ when the $\mathrm{N}$-terminal $\alpha$-helix is located within the pore [18-20]. The stretch of multiple glycine residues $\left({ }^{21}\right.$ GlyTyrGlyPheGly $\left.{ }^{25}\right)[1,5]$ connecting the N-terminal domain to $\beta$-strand 1 of the barrel is thought to provide the flexibility required for $\mathrm{N}$-terminal region translocation out of the internal pore of the channel [22]. The reported results suggest that the $\mathrm{N}$-terminal region mobility is involved in channel gating, interaction with anti-apoptotic proteins, and VDAC1 dimer formation [22], as well as serving the interaction site of apoptosis-regulating proteins of the $\mathrm{Bcl}-2$ family (i.e., $\mathrm{Bax}, \mathrm{Bcl}-2$, and $\mathrm{BCl}-\mathrm{xL}$ ) $[22,23-26]$ and hexokinase (HK) $[23,27]$.

Purified and membrane-embedded VDAC1 is able to assemble into dimers, trimers, tetramers, hexamers, and higher-order moieties $[1,28-36]$. The contact sites between VDAC1 molecules in dimers and higher oligomers were identified [37]. Under physiological conditions, VDAC1 is present as a monomer and dimer, with a contact site involving $\beta$-strands 1,2 , and 19 . However, upon apoptosis induction, VDAC1 dimers undergo conformational changes to assemble into higher oligomeric states with contact sites also involving $\beta$-strands 8 and 16 [37]. VDAC1 oligomerization has been proposed to play important physiological roles in the regulation of VDAC1 function, including contributing to stabilizing the protein [38], serving as a platform for other proteins that oligomerize, such as $\mathrm{HK}$ [36] and creatine kinase [39], and finally, in mediating Cytochrome $c$ release and the binding of apoptosis-regulating proteins $[23,28,36]$ (see below).

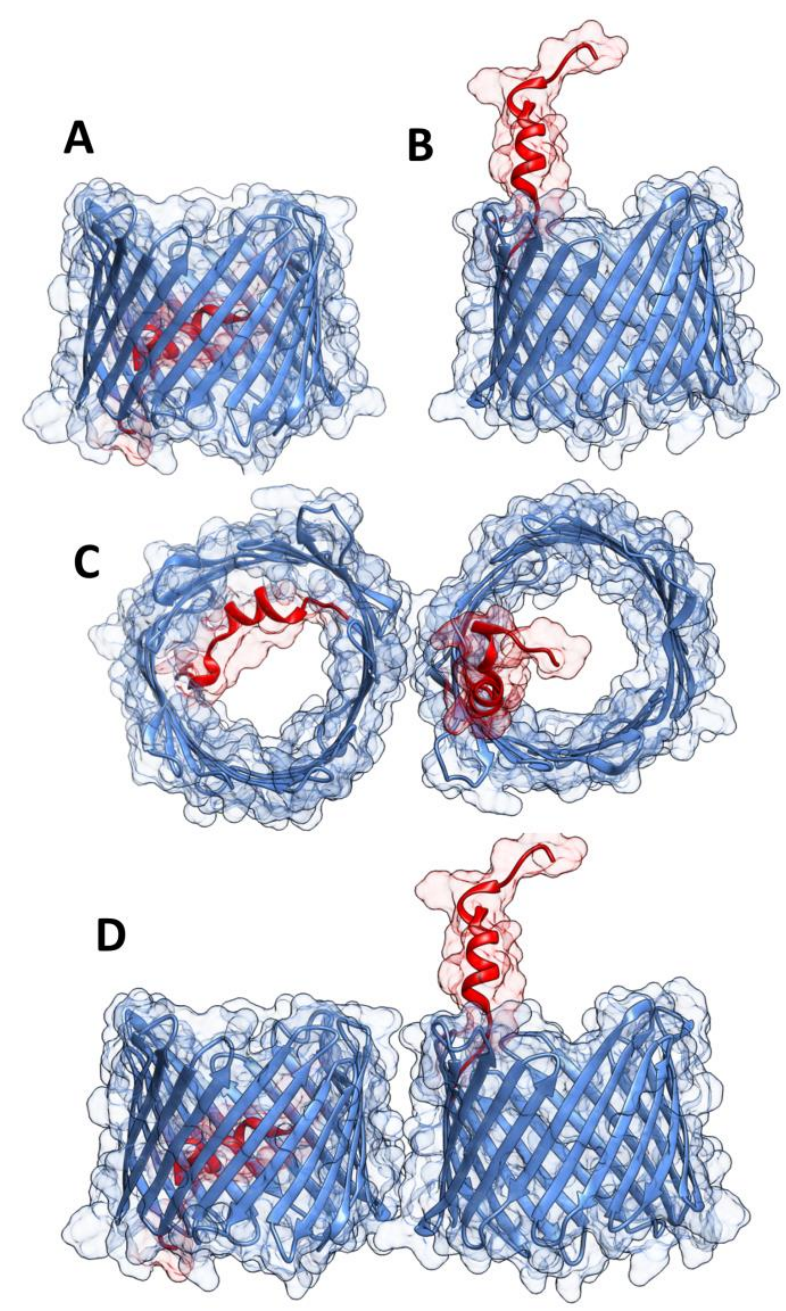

FIGURE 1: Three-dimensional structure of VDAC1. VDAC1 monomer and dimer structures. (A) Side-view of the crystal structure of VDAC1 (PDB code: 3EMN). The $\beta$-barrel is formed by $19 \beta$ strands and the $\mathrm{N}$-terminal domain (colored red) is folded into the pore interior. (B) A proposed model for the conformation of VDAC1 with its N-terminal on the outside of the VDAC1 pore. (C) Top-view of VDAC1 dimer with the N-terminal helix nested inside the VDAC1 pore in one monomer and outside of the pore in the other. (D) Side-view of proposed dimer of VDAC1. Figures were prepared using PyMOL software. 
VDAC1 has been purified from mitochondria isolated from liver, brain, and other tissues [40], and its channel properties were characterized following reconstitution into a planar lipid bilayer (PLB). Such bilayer-reconstituted VDAC1 assumes a variety of voltage-dependent conducting states, with different selectivities and permeabilities. VDAC1 shows symmetrical bell-shaped voltage-dependent conductance. At low voltages $(-20$ to $+20 \mathrm{mV})$, VDAC1 exists in a high conductive state ( $\sim \mathrm{nS}$ at $1 \mathrm{M} \mathrm{KCl}$ ), and shows a preference for transporting anions over cations, while at high positive or negative potentials (> $40 \mathrm{mV}$ ), VDAC1 switches to lower conductance states permeable to small ions $[41,42]$. VDAC1 is permeable to small ions (e.g. $\mathrm{Cl}^{-}, \mathrm{K}^{+}$, $\mathrm{Na}^{+}$), and also to large anions, such as glutamate [41] and ATP [43], and to large cations, such as acetylcholine and dopamine [41].

The interactions of VDAC1 with $\mathrm{Ca}^{2+}$, ATP, glutamate, $\mathrm{NADH}$, and different proteins were suggested to modulate its activity [44-47]. VDAC1 has been shown to be phosphorylated by protein kinase A (PKA) [48] and protein kinase $C(P K C) \varepsilon$ [49], and VDAC1 and VDAC2 were found to be phosphorylated at a particular Tyr residue under hypoxic conditions [50].

\section{VDAC1, A MULTI-FUNCTIONAL CHANNEL CONTROL- LING CELL ENERGY AND METABOLISM}

The OMM, the interface between the cytosol and a mitochondrion, is also a limiting boundary for modulating cell bioenergetics, mediated via VDAC1. The metabolites and ions that reach the matrix must first cross the OMM to reach the mitochondrial intermembrane space (IMS), from where they are then transported by about 53 secondary transport proteins called mitochondrial carriers (MCs). The mitochondrial carrier proteins of the family SLC25 (solute carrier family 25 , located in the inner mitochondrial membrane (IMM)) are substrate-specific and mediate electrochemical, chemical and membrane potential gradientdependent transport. The SLC25 family includes carriers for Pi (PiC), ADP/ATP (ANT) and aspartate/glutamate, pyruvate, acyl carnitine, oxoglutarate, and citrate, among others [51] On the other hand, VDAC1 is the sole channel mediating the flux of ions, nucleotides and other metabolites up to $\sim 5,000$ Da (e.g. pyruvate, malate, succinate, NADH/NAD ${ }^{+}$) across the OMM, as well as hemes and cholesterol [1, 52]. Thus, at the OMM, VDAC1 is perfectly positioned to function as gatekeeper for the entry and exit of substrates and products into and out of the mitochondria, and to interact with proteins that mediate and regulate the integration of mitochondrial functions with other cellular activities [1, 2931, 42, 53, 54] (Fig. 2).

VDAC1 allows the shuttling of ATP/ADP and $\mathrm{NAD}^{+} / \mathrm{NADH}$, with mitochondria-generated ATP being transported to the cytosol in exchange for ADP, which is utilized in oxidative phosphorylation (OXPHOS) to generate ATP. As such, VDAC1 controls the electron transport chain [1] (Fig. 2), as well as the normal flow of metabolites [55]. The importance of VDAC1 in channeling ATP from the mitochondria to kinases has been presented in several stud- ies. These showed that VDAC1 interacts with HK and creatine kinase (CrK) to convert newly generated ATP into highenergy storage forms, like glucose-6-phosphate (G-6-P) and creatine phosphate in brain and muscle, respectively. The interaction of VDAC1 with HK mediates coupling between OXPHOS and glycolysis, while at the contact sites between the IMM and OMM, VDAC1 forms a complex with the adenine nucleotide translocase (ANT), and CrK [56]. Dimeric $\alpha \beta$-tubulin was proposed as a regulator of VDAC1 permeability to ATP, with heterodimers of $\alpha \beta$-tubulin decreasing the passage of ATP through the channel [57]. The importance of VDAC1 in cell energy and metabolism homeostasis is reflected in the findings that closure of VDAC [55] or down-regulation of VDAC1 expression decreased metabolite exchange between mitochondria and the cytosol and inhibited cell growth [58, 59]. Moreover, VDAC1 is overexpressed in many cancer cells [32], as discussed below.

Cholesterol is another metabolite transported across the OMM [60] (Fig. 2), with VDAC1 being considered as a necessary component of a multi-protein complex, the transduceosome, involved in the process. In addition to VDAC1, the transduceosome also includes the OMM highaffinity cholesterol-binding protein translocator protein (TSPO) and the steroidogenic acute regulatory protein (StAR) [61] (Fig. 2). Cholesterol synthesis is highly elevated in various cancer cells, with hepatocellular carcinoma cells containing 2-10-fold more mitochondrial cholesterol (mainly in the OMM) than found in liver mitochondria [62]. The increased binding of $\mathrm{HK}$ to the mitochondria may increase synthesis and uptake of cholesterol into the mitochondria of cancer cells [63]. At high levels, cholesterol can reduce the activity of membrane-associated proteins and thus inhibit the metabolic functions of VDAC1 [64]. As such, VDAC1 is involved in cholesterol synthesis and transport, as well as being subject to cholesterol-mediated regulation.

Finally, it appears that VDAC1 is also part of a complex mediating the transport of fatty acids through the OMM in rat liver mitochondria [65]. In this case, it is hypothesized that VDAC1 acts as an anchor, linking the long-chain acylCoA synthetases (ACSLs) at the OMM to carnitine palmitoyltransferase 1a (CPT1a), which faces the IMS. According to the proposed model, upon activation by ACSL, VDAC1 transfers acyl-CoAs across the OMM to the IMS, where they are converted into acylcarnitine by CPT1a. Moreover, recently it was shown that fatty acid accumulation in hepatocytes leads to a lack of phosphorylation by GSK-3 $\beta$, indicating interplay between lipids and VDAC function [66]. Furthermore, it was recently proposed that VDAC behaves as a lipid sensor [67].

\section{CANCER, METABOLISM, MITOCHONDRIA, AND VDAC1}

One of the main functions of the telomere is to prevent the metabolic reprogramming in cancer cells that require plasticity of the metabolic machinery, regardless of cellular or tissue origin, a critical process that promotes cell proliferation with alterations seen in the metabolism of several substrates, including glucose and glutamine $[68,69]$. In the 


\section{ER-Mito $\mathrm{Ca}^{2+}$ transport}

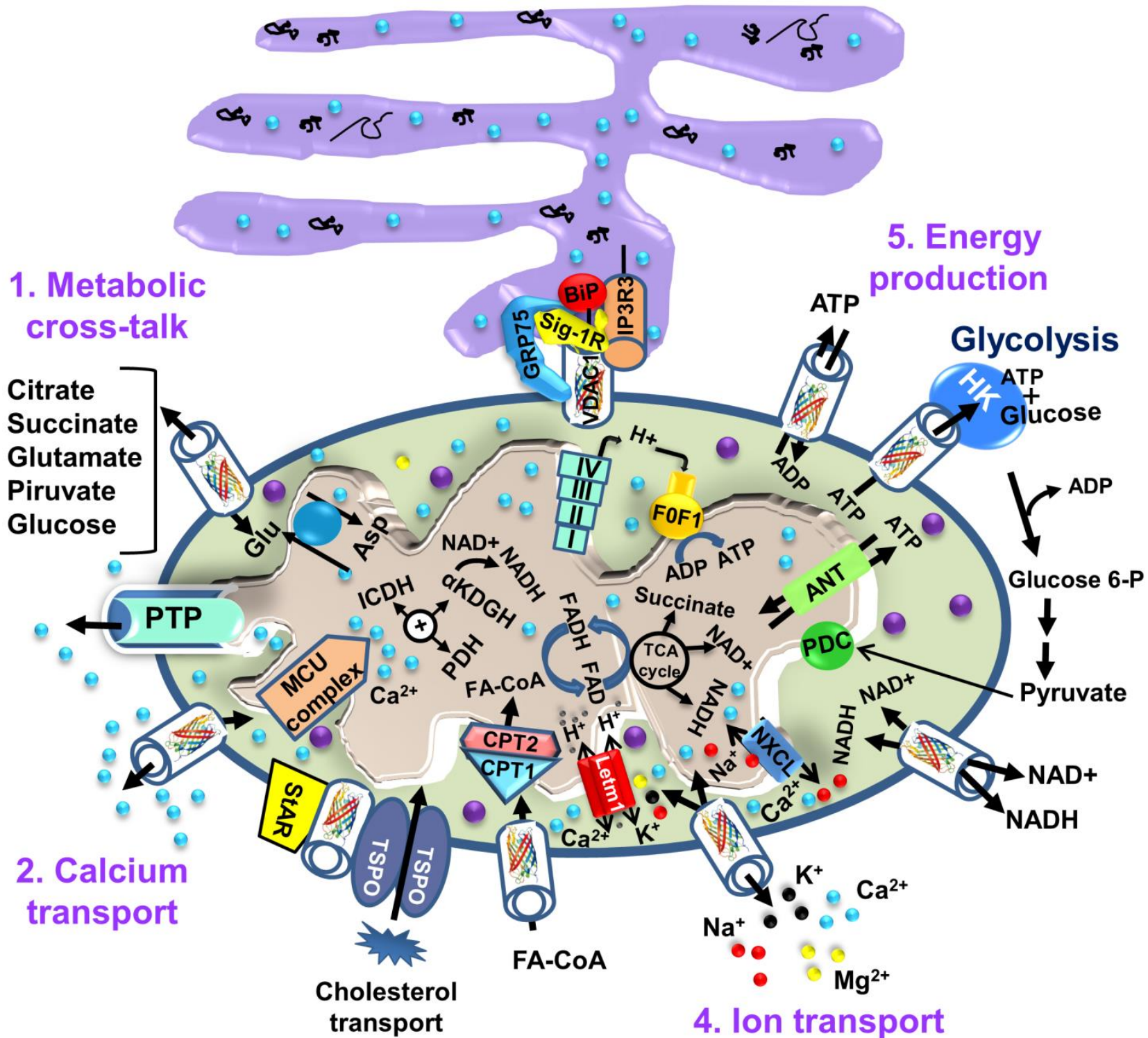

\section{Lipid metabolism}

FIGURE 2: VDAC1 as a multi-functional channel involved in metabolite, cholesterol and $\mathrm{Ca}^{2+}$ transport, energy production and in ER-mitochondria structural and functional association. The functions of VDAC1 in cell life include control of the metabolic cross-talk between the mitochondria and the rest of the cell energy production, regulation of glycolysis via binding of $\mathrm{HK}, \mathrm{Ca}^{2+}$ signaling and cholesterol transport. The various functions of VDAC1 in the cell and mitochondria functions are presented. These include: $\mathbf{1}$. Control of the metabolic cross-talk between mitochondria and the rest of the cell; $\mathbf{2}$. Transport of $\mathrm{Ca}^{2+}$ to and from the IMS and acting in $\mathrm{Ca}^{2+}$ signaling; 3. Lipid metabolism; 4. Transport of ions, such as $\mathrm{Mg}^{2+}, \mathrm{Zn}^{+}, \mathrm{Na}^{+}$and $\mathrm{K}^{+} ; \mathbf{5}$. Mediating cellular energy production by transporting ATP/ADP and NAD $/ \mathrm{NADH}$ and acyl-CoA (FA-COA) from the cytosol to and from the IMS, and regulating glycolysis via association with HK; 6. Structurally and functionally contributing to ER-mitochondria contacts, mediating $\mathrm{Ca}^{2+}$ transport from the ER to mitochondria. Ca ${ }^{2+}$ influx and efflux systems in the IMM are shown. The mitochondrial $\mathrm{Ca}^{2+}$ uniporter (MCU), in association with a calcium-sensing accessory subunit (MCU1), mediates $\mathrm{Ca}^{2+}$ transport from the IMS into the matrix. The ryanodine receptor (RyR) in the IMM mediates $\mathrm{Ca}^{2+}$ influx. $\mathrm{NCLX}$, a Na $/ \mathrm{Ca}^{2+}$ exchanger, mediates $\mathrm{Ca}^{2+}$ efflux from the matrix to the IMS. High levels of matrix $\mathrm{Ca}^{2+}$ trigger the opening of the PTP, a fast $\mathrm{Ca}^{2+}$ release channel. Molecular fluxes are indicated by arrows. The function of $\mathrm{Ca}^{2+}$ in regulating energy production is mediated via activation of the TCA cycle enzymes pyruvate dehydrogenase (PDH), isocitrate dehydrogenase (ICDH) and $\alpha$-ketoglutarate dehydrogenase $(\alpha-K G D H)$, leading to enhanced activity of the TCA cycle. The electron transport chain (ETC) and the ATP synthase $\left(\mathrm{F}_{0} \mathrm{~F}_{1}\right)$ are also presented. VDAC1 mediates the transfer of acyl-CoAs across the OMM to the IMS, where they are converted into acylcarnitine by CPT1a for further processing by $\beta$-oxidation. VDAC1 is involved in cholesterol transport by being a constituent of a multi-protein complex, the transduceosome, containing StAR/TSPO/VDAC1.The ER-mitochondria association is presented with key proteins indicated. These include the inositol 3 phosphate receptor type $3\left(\mathrm{IP}_{3} \mathrm{R} 3\right)$, the sigma 1 receptor (Sig1R) (a reticular chaperone), binding immunoglobulin protein (BiP), the ER HSP70 chaperone, and glucoseregulated protein 75 (GRP75). IP $P_{3}$ activates $\mathrm{IP}_{3} \mathrm{R}$ in the ER to release $\mathrm{Ca}^{2+}$ that is directly transferred to the mitochondria via VDAC1. 
1920's, Otto Warburg demonstrated increased lactic acid production resulting from high glycolysis in tumors, as compared to non-proliferating cells. The Warburg effect described a metabolic phenotype characterized by enhanced glycolysis and suppression of mitochondrial metabolism at any level of oxygen. However, although enhanced glycolysis is a prominent feature of most tumor cells, the mitochondria of cancer cells maintain a membrane potential, oxidize respiratory substrates, and generate NADH and ATP, among other functional parameters [70-73]. The view of cancer as a metabolic disease that originated with the experiments of Otto Warburg was gradually displaced by the concept of cancer as a genetic disease. Recently, evidence supporting a general hypothesis that genomic instability and essentially all hallmarks of cancer, including aerobic glycolysis, can be linked to impaired mitochondrial function and energy metabolism, has been reviewed $[74,75]$. Interestingly, no specific gene mutations or chromosomal abnormalities are common to all cancers [76], while nearly all cancers display aerobic glycolysis, regardless of their tissue or cellular origin. The view of cancer as primarily being a metabolic disease will impact approaches to cancer management and prevention.

Malignant cancer cells typically display high rates of glycolysis, even when fully oxygenated (aerobic glycolysis), and an altered redox balance [77-79]. To increase glycolysis, cancer cells up-regulate the transcription of genes involved in the glycolytic pathway (i.e., glucose transporters, glycolytic enzymes, etc.). Cancer cells in fact use both glycolysis and OXPHOS, with the ratio depending on the prevalent normoxic or hypoxic environmental conditions and their capacity to express adequate levels of oncogenes and tumor suppressor gene products for cell growth [80]. By regulating the metabolic and energetic functions of mitochondria, VDAC1 can, therefore, control the fate of cancer cells. Mitochondrial-bound $\mathrm{HK}$, considered the rate-limiting enzyme of glycolysis, is over-expressed in cancer [1, 81, 82]. The association of HK with VDAC1 offers several advantages to cancer cells $[1,32]$, such as direct access to mitochondrial sources of ATP, assumption of the role of an anti-apoptotic protein, reducing intracellular levels of reactive oxygen species (ROS) and increasing synthesis and uptake of cholesterol. The HK-VDAC1 complex formation is regulated by Akt [83] and glycogen synthase kinase 3 beta (GSK3 3 ), while the HK-VDAC complex is disrupted by VDAC phosphorylation [84].

In recent years, cumulative evidence indicates that free tubulin in cancers cells interacts with VDAC $[70,85]$. Dimeric $\alpha \beta$-tubulin decreases the conductance of bilayerreconstituted VDAC1 and VDAC2 and also decreases respiration in cardiac myocytes and isolated brain mitochondria $[86,87]$. In cancer cells, microtubule destabilization induced by colchicine or microtubule stabilization by paclitaxel increased and decreased free tubulin, leading to decreased and increased $\Delta \Psi_{\mathrm{m}}$, respectively [70]. The dynamic regulation of $\Delta \Psi_{\mathrm{m}}$ by free tubulin appears to occur only in cancer cells. It has been proposed that the dynamic changes of $\Delta \Psi_{\mathrm{m}}$ brought about by free tubulin in tumor cells are related to $\alpha \beta$-tubulin heterodimers modulating VDAC conductance (Fig. 3) [70].

VDAC1 and VDAC2 isolated after VDAC2/3 or VDAC1/3 double knockdown in cancer cells were shown to be sensitive to tubulin inhibition. Even more, VDAC1 knockdown in tumor cells decreased $\triangle \Psi \mathrm{m}$, indicating that VDAC1 is critical for the maintenance of $\Delta \Psi_{\mathrm{m}}$ and is regulated by endogenous free tubulin [85]. Inhibition of VDAC1 conductance by free tubulin is a main contributor to the suppression of mitochondrial metabolism in the Warburg phenotype. Recently, the VDAC-tubulin interaction was proposed to serve as a metabolic switch to increase or decrease mitochondrial metabolism, ATP generation and cytosolic ATP/ADP ratios [88]. High and low cytosolic ATP/ADP ratios inhibit or favor aerobic glycolysis, respectively. Thus, blockage of the inhibitory effect of tubulin on VDAC by VDAC-tubulin antagonists promotes mitochondrial metabolism and reverses the Warburg phenotype (Fig. 3). The VDAC-tubulin interaction represents a new pharmacological target for the development of novel anti-cancer agents [88].

\section{Silencing VDAC1 expression reduces cell energy homeo- stasis, inhibiting cells and tumor growth}

As cellular metabolic and energy reprogramming are cancer hallmarks essential for tumor progression, and VDAC1 is a key regulator of these processes [1, 30, 32, 47, 52, 89], down-regulation of VDAC1 expression is expected to impact cancer cell growth. VDAC1 down-regulation results in reduced metabolite exchange between the mitochondria and the cytosol, leading to inhibited cell growth. Indeed, silencing VDAC1 expression reduced cellular ATP levels and cell growth, with tight correlation between cell growth and cellular ATP levels being seen [58]. shRNA directed against hVDAC1 inhibited the development of a HeLa cervical tumor [90]. Nano-molar concentrations of a single siRNA specific to human VDAC1 silenced VDAC1 expression and inhibited the growth of various cancer cell types. In fact, such treatment inhibited solid tumor development and growth in lung cancers (over $90 \%$ ) both in vitro and in vivo [59].

Recently, a global change in tumor hallmarks upon silencing VDAC1 expression was demonstrated in glioblastoma multiform (GBM) [91]. Using a sub-cutaneous or an intracranial-orthotopic GBM model, we demonstrated that si-VDAC1 inhibited tumor growth, with the residual tumor showing reversed oncogenic properties, such as reprogramed metabolism, angiogenesis, epithelial-mesenchymal transition (EMT), invasiveness and stemness, leading to differentiation into neuron- and astrocyte-like cells [91] (Fig. 4). These VDAC1 depletion-mediated effects involved alterations in transcription factors (TFs) that regulate signaling pathways associated with cancer hallmarks, allowing for attacks on the interplay between metabolism and oncogenic signaling networks (to be explored here), leading to cancer stem cell (CSC) differentiation into neuronal-like cells [91]. 


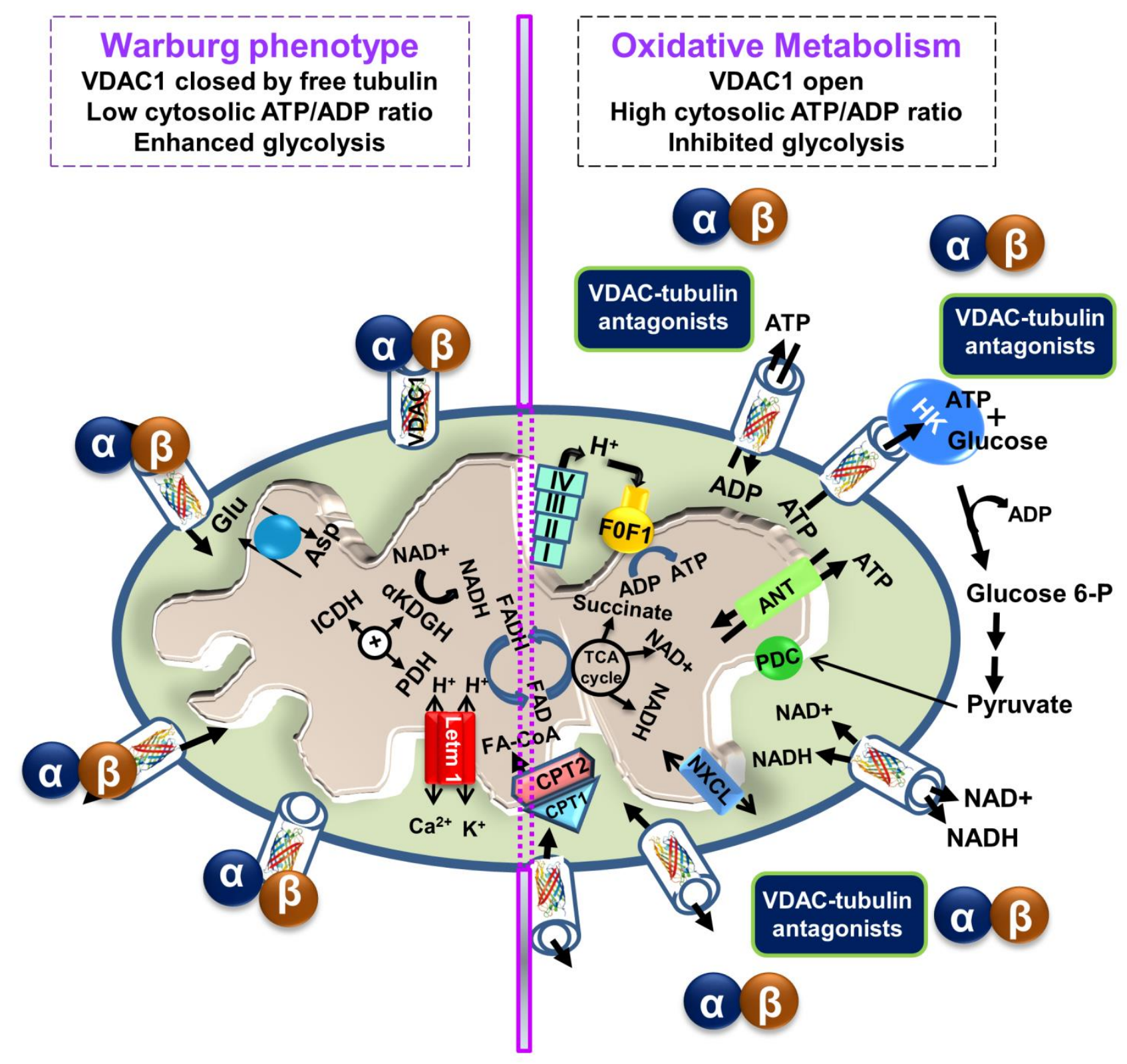

FIGURE 3: VDAC1-tubulin interaction: a metabolic switch to modulate mitochondrial metabolism in cancer cells. In cancer cells, high levels of free tubulin close VDAC1, decreasing the flux of metabolites, ATP and ADP through the OMM. VDAC1 closing leads to low generation of mitochondrial ATP and subsequently, to a low cytosolic ATP/ADP ratio that favors glycolysis in the Warburg phenotype. Erastin, a VDAC-tubulin antagonist, opens VDAC1 by blocking the inhibitory effect of free tubulin. VDAC1 opening leads to increased mitochondrial metabolism and to a high cytosolic ATP/ADP ratio that inhibits glycolysis and reverts the Warburg phenotype. $\alpha \beta$ indicates tubulin heterodimers.

\section{microRNA-mediated regulation of VDAC1}

A number of microRNAs (miRNAs) targeting VDAC1 were reported and found to be modified under pathological conditions. miR-29a [92] and miR-320a [93] have been shown to reduce VDAC1 expression levels. Another miRNA species, miR-7, was shown to inhibit VDAC1 expression, proliferation and metastasis in hepatocellular carcinoma [94], possibly by affecting the permeability transition pore (PTP) [95]. Recently, IncRNA-H19/miR-675 was reported to regulate high glucose-induced apoptosis by targeting
VDAC1, and thus provides a novel therapeutic strategy for the treatment of diabetic cardiomyopathy [96].

The therapeutic potential of a number of miRNAs able to regulate VDAC1 expression levels is clear in view of the observation that VDAC1 over-expression is associated with a variety of pathological conditions, including Alzheimer's disease (AD) [97-99], and cardiovascular diseases (CVDs) [100]. In addition, hyperglycemia has been shown to increase VDAC1 expression in $\beta$-cells [101] and in the kidney [102]. 


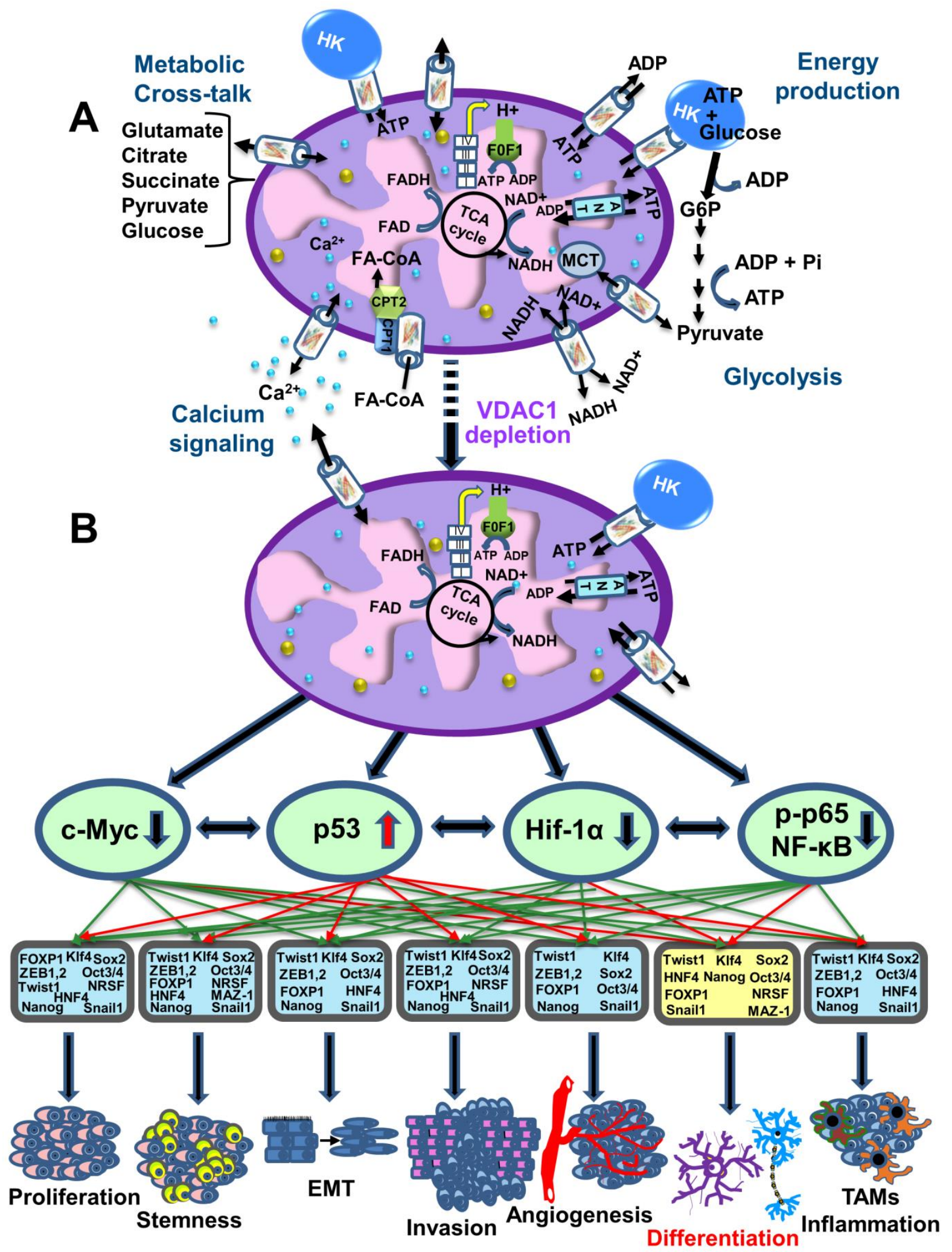

FIGURE 4: VDAC1-depletion and metabolic reprogramming leading to alterations in key transcription factor levels and biological processes: a reversal of oncogenic properties and cell differentiation. (A) A schematic presentation of mitochondria in a cancer cell before treatment with hVDAC1 siRNA. Here, cancer cells maintain homeostatic energy and metabolic states, with HK bound to VDAC1 accelerating glycolysis and mitochondrial function to allow sufficient ATP and metabolite precursor levels to support cell growth and survival. (B) VDAC1 depletion leads to dramatic decreases in energy and metabolite generation. This leads to changes in master metabolism regulator ( $\mathrm{p} 53$, HIF1- $\alpha$, c-Myc and NF-kb, P65) expression levels, which alters the expression of transcription factors associated with stemness, EMT, cell proliferation, invasion, TAMs and angiogenesis, while leading to differentiation into astrocyte- or neuron-like cells. 


\section{VDAC1 AS A PLAYER IN MITOCHONDRIA-MEDIATED} APOPTOSIS

Programmed cell death, or apoptosis, is the biological process by which a cell rapidly proceeds towards death upon receiving specific stimuli. The apoptotic machinery in humans consists of a molecular network comprising a large number of proteins that regulate a cascade of events leading to apoptosis through multiple parallel pathways. It is well accepted that mitochondria serve as integrators and amplifiers of apoptosis by mediating and regulating the release of pro-apoptotic proteins and/or disrupting cellular energy metabolism [103]. Upon transfer of an apoptotic signal into the cell, mitochondrial membrane permeability changes so as to facilitate the release of apoptogenic proteins, such as cytochrome $c$ (Cyto $c$ ), apoptosis-inducing factor (AIF), and SMAC/Diablo, from the IMS into the cytosol $[54,103]$. These proteins participate in complex processes, resulting in the activation of proteases and nucleases, leading to protein and DNA degradation and cell death. However, it remains unclear how these apoptotic initiators cross the OMM and are thus released into the cytosol. Several hypotheses regarding the mechanism of mitochondria-mediated apoptosis have been proposed (Fig 5) (for reviews, see $[1,30,104])$. The major models include OMM rupture and non-specific release of IMS proteins into the cytosol $[55,105,106]$, opening of the PTP in response to over-production of ROS or $\mathrm{Ca}^{2+}$ overload [107], a large channel formed by Bax and/or Bak oligomers [108, 109], a channel formed by hetero-oligomers of VDAC1 and Bax $[110,111]$ or VDAC1 oligomers (Fig. 5) [23, 28-31, 36, 104, $112,113]$.

All of the apoptotic proteins known to translocate to the cytoplasm following an apoptotic stimulus reside in IMS. Thus, only the permeability of the OMM needs to be modified for their release [114-117]. Hence, VDAC1, as an OMM channel, could mediate Cyto $c$ release. Indeed, VDAC1 is now accepted as a key player in mitochondriamediated apoptosis, with VDAC1 silencing or overexpression affecting apoptosis induction $[1,23,33,118$ 122]. Exogenous over-expression of VDAC from various sources was found to induce apoptotic cell death regardless of cell type [113, 118-122]. VDAC1 over-expressioninduced cell death was prevented by RuR $[122,123], \mathrm{Bcl} 2$, DIDS [120] or by over-expression of HK-I [118, 122, 124], with all these agents directly interacting with VDAC1. Finally, reducing VDAC1 expression by siRNA efficiently prevented cisplatin-induced apoptosis and Bax activation in non-small cell lung cancer (NSCLC) cells [125], and inhibited selenite-induced PTP opening in HeLa cells [126]. VDAC1siRNA also attenuated endostatin-induced apoptosis [127]. In addition to the evidence above, release of Cyto $c$ via purified VDAC reconstituted into Cyto $c$-encapsulating liposomes has been demonstrated [36, 128, 129]. It is thus proposed that VDAC1 oligomerization is a key step in the release of the pro-apoptotic proteins from the IMS to the cytosol [23, 28-31, 36, 104, 112, 113].
A VDAC1 oligomeric structure as a Cyto $c$ release pathway When considering models of VDAC1-mediated protein release, the molecular sizes of the released proteins (12 to $100 \mathrm{kDa})$ and the diameter of the VDAC1 pore (2.6-3.0 nm) should be considered. The VDAC1 pore can allow passage of nucleotides and small molecules but is too small for the passage of a folded protein like Cyto $c$. As such, we proposed the formation of a large protein-conducting channel within a VDAC1 homo-oligomer serving as the Cyto $c$ release route. Indeed, upon apoptosis induction by various stimuli, VDAC1 undergoes conformational changes and oligomerization, followed by Cyto $c$ release, and finally, apoptosis [29, 33, 36, 118, 129].

Apoptosis induction leads to VDAC1 oligomerization regardless of the cell type or apoptosis inducer used, including staurosporine (STS), curcumin, $\mathrm{As}_{2} \mathrm{O}_{3}$, etoposide, cisplatin, selenite, $\mathrm{H}_{2} \mathrm{O}_{2}$ or UV light, all affecting mitochondria yet acting via different mechanisms [28, 112]. Moreover, shifting the equilibrium towards the VDAC1 oligomeric state upon over-expression of the protein in the absence of apoptosis stimuli resulted in release of pro-apoptotic proteins, leading to cell death, regardless of cell type, in a manner that could be inhibited by anti-apoptotic proteins $[23,33,113,118-122]$. The specific lipid composition of the OMM significantly enhances VDAC1 oligomerization [130], while p53 also promotes VDAC1 oligomerization [131].

Several VDAC1-interacting molecules inhibit both apoptosis and VDAC1 oligomerization as induced by various stimuli $[28,104,112,113,119,120,122,132,133]$. These include 4,4 diisothiocyanostilbene-2,2-disulfonic acid (DIDS), 4-acetamido-4-isothiocyanato-stilbene-2,2disulfonic acid (SITS), 4,4' diisothiocyanatodihydrostilbene-2,2'-disulfonic acid (H2DIDS), 4,4'dinitrostilbene-2,2'-disulfonic acid (DNDS), and diphenylamine-2-carboxylate (DPC). Similarly, the newly developed VDAC1-interacting molecules AKOS-022 and VBIT-4 prevented VDAC1 oligomerization and apoptosis as induced by various means and in several cell lines [134]. These compounds also protected against apoptosis-associated mitochondrial dysfunction, specifically restoring dissipated mitochondrial membrane potential, and thus cell energy and metabolism, decreasing ROS production, and preventing disruption of intracellular $\mathrm{Ca}^{2+}$ levels. The use of these apoptosis inhibitors thus supports the tight coupling between VDAC1 oligomerization and apoptosis induction. Inhibiting apoptosis at an early stage via prevention of VDAC1 oligomerization may be an effective approach for blocking or slowing apoptosis in neurodegenerative disorders $[135,136]$ and various cardiovascular diseases, where enhanced apoptosis also occurs [137-139].

To conclude, it is proposed that VDAC1 exists in a dynamic equilibrium between the monomeric and oligomeric states, with apoptosis inducers or VDAC1 over-expression shifting the equilibrium towards oligomerization. Thus, the cellular VDAC1 expression level and its oligomeric state are crucial factors in the process of mitochondria-mediated apoptosis. 


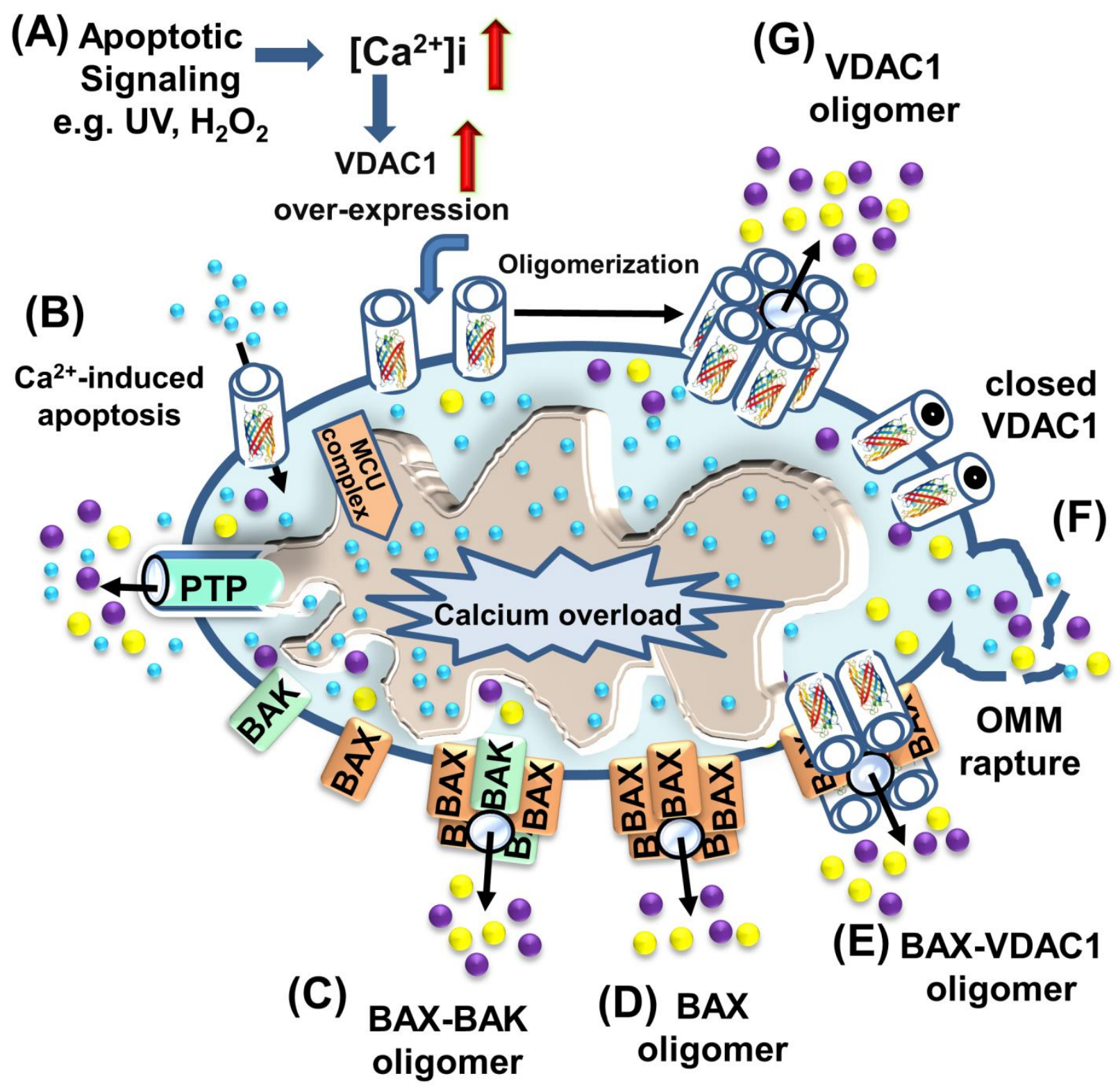

FIGURE 5: VDAC1 function in cell death, with apoptosis inducers enhancing VDAC1 expression levels and oligomerization. A schematic representation of VDAC1 function in cell death - Different models for the release of apoptogenic proteins, such as Cyto $c$ (purple) and AIF (yellow), are shown. (A) Proposed model suggesting that apoptotic stimuli or conditions cause enhanced VDAC1 expression via increases in [Ca $\left.{ }^{2+}\right]$ levels or transcription factors, leading to activation of the VDAC1 promoter. The increase in VDAC1 expression shifts the equilibrium towards the VDAC1 oligomeric state, forming a hydrophilic protein-conducting channel capable of mediating the release of apoptogenic proteins (e.g., Cyto $c$ and AIF) from the mitochondrial IMS to the cytosol. (B) Mitochondrial $\mathrm{Ca}^{2+}$ overload induces apoptosis. $\mathrm{Ca}^{2+}$ transport across the OMM, as mediated by VDAC1, and then across the IMM, as mediated by the MCU, leads to $\mathrm{Ca}^{2+}$ overload in the matrix. This, in turn, causes dissipation of the membrane potential, mitochondrial swelling, PTP opening, Cyto c/AIF release and the triggering of apoptotic cell death. (C) Bax/Bak oligomerization and activation, forming a route for Cyto C/AIF release. (D) Bax activation leads to its association with the OMM, followed by its oligomerization as a large oligomer/complex, forming a Cyto c/AIF-conducting channel. (E) The interaction of the pro-apoptotic protein Bax with VDAC1 forms hetro-oligomers that mediate Cyto C/AIF release. (F) Prolonged VDAC1 closure leads to mitochondrial matrix swelling and OMM rupture, resulting in the appearance of a non-specific release pathway for apoptogenic proteins.

The mode of action of apoptotic stimuli and VDAC1 overexpression - a new concept

Several studies have demonstrated that the induction of apoptosis by various reagents is accompanied by an increase in the level of VDAC1 expression [54]. These include arbutin (hydroquinone-O-beta-D-glucopyranoside), a tyrosinase inhibitor that induces apoptosis in A375 human malignant melanoma cell by causing VDAC1 over-expression [140]. Up-regulation of VDAC1 expression was noted in acute lymphoblastic leukemia (ALL) cell lines following 
prednisolone treatment [141]. Somatostatin up-regulated the expression of VDAC1 and VDAC2 in the LNCaP prostate cancer cell line [142]. Up-regulation of VDAC1 expression levels was also induced by the hepatitis E virus ORF3 protein [143]. Also, both UV irradiation and ROS were shown to up-regulate VDAC1 expression [144-146] that was prevented by the ROS chelator epigallocatechin [144]. Cisplatin induced VDAC1 over-expression in a cisplatin-sensitive cervix squamous cell carcinoma cell line (A431), while down-regulation of VDAC1 was noted in a cisplatinresistant cell line (A431/Pt) [147]. Up-regulation of VDAC expression was proposed to mediate the actions of vorinostat, a histone deacetylase inhibitor that induced synergistic anti-proliferative and pro-apoptotic effects in NSCLC cells in combination with EGFR-tyrosine kinase inhibitors [148]. Finally, apoptosis induction by $\mathrm{H}_{2} \mathrm{O}_{2}$, etoposide, cisplatin, selenite and UV irradiation all led to enhanced VDAC1 expression levels, which was accompanied by VDAC1 oligomerization, Cyto $c$ release and apoptosis [54, 112, 113].

As apoptosis induction by agents such as STS, $\mathrm{As}_{2} \mathrm{O}_{3}$, and selenite disrupt $\left[\mathrm{Ca}^{2+}\right] \mathrm{i}$ homeostasis and energy production [112, 113, 149], apoptosis-induced VDAC1 upregulation is proposed to be mediated by an increase in $\left[\mathrm{Ca}^{2+}\right]$ i. Indeed, we have shown that pro-apoptotic-agents induce cell death through $\mathrm{Ca2+-dependent} \mathrm{up-regulation}$ of VDAC1 expression levels [54, 112, 113]. Direct elevation of [Ca2+]i by the $\mathrm{Ca}^{2+}$-mobilizing agents $\mathrm{A} 23187$, ionomycin and thapsigargin also resulted in VDAC1 over-expression, VDAC1 oligomerization and apoptosis [112, 113]. In contrast, decreasing $\left[\mathrm{Ca}^{2+}\right] \mathrm{i}$ using the cell-permeable $\mathrm{Ca}^{2+}$ chelating reagent BAPTA-AM inhibited VDAC1 overexpression, VDAC1 oligomerization and apoptosis. Thus, the increase in $\left[\mathrm{Ca}^{2+}\right] \mathrm{i}$ induced by apoptosis stimuli was found to be a pre-requisite for induction of VDAC1 overexpression and apoptosis [112, 113]. The over-expressed VDAC1 forms oligomers and this triggers Cyto $c$ release and then cell death. The following new concept of apoptosis induction is thus proposed [112, 113]: Apoptosis inducers $\rightarrow$ increased $\left[\mathrm{Ca}^{2+}\right] \mathrm{i} \rightarrow$ enhanced VDAC1 expression levels $\rightarrow$ VDAC1 oligomerization $\rightarrow$ Cyto $c$ release $\rightarrow$ apoptosis.

As such, up-regulation of the expression of VDAC1 may represent a new common mode of action of apoptosis induction.

\section{VDAC1 AND $\mathrm{CA}^{2+}$ HOMEOSTASIS}

Mitochondria serve as a major hub for cellular $\mathrm{Ca}^{2+}$ homeostasis, regulating oxidative phosphorylation and modulating cytosolic $\mathrm{Ca}^{2+}$ signals of cell death and secretion [150, 151]. Mitochondria can rapidly sequester large amounts of $\mathrm{Ca}^{2+}$ at the expense of the membrane potential across the IMM and mediate $\mathrm{Ca}^{2+}$ efflux. $\mathrm{Ca}^{2+}$ is an essential co-factor for several rate-limiting TCA enzymes (i.e., pyruvate dehydrogenase, isocitrate dehydrogenase, and $\alpha$-ketoglutarate dehydrogenase) located in the matrix, such that intramitochondrial $\mathrm{Ca}^{2+}$ controls energy and metabolism. To reach the matrix, $\mathrm{Ca}^{2+}$ must cross both the OMM and the IMM, in a manner mediated by several proteins. VDAC1 acts in the OMM, whereas the mitochondrial $\mathrm{Ca}^{2+}$ uniporter (MCU) $[152,153]$ and the $\mathrm{Na}^{+} / \mathrm{Ca}^{2+}$ exchanger, NCLX, the major $\mathrm{Ca}^{2+}$ efflux mediator [154], are both found in the IMM.

The function of VDAC1 in regulation of cell $\mathrm{Ca}^{2+}$ homeostasis was recently summarized [155]. VDAC1 in the OMM is highly $\mathrm{Ca}^{2+}$-permeable and transports $\mathrm{Ca}^{2+}$ into and out of the IMS [156-159], consequently allowing $\mathrm{Ca}^{2+}$ access to IMM transporters. Ruthenium red (RuR) [157, 160, 161], ruthenium amine binuclear complex (Ru360) [161], the photo-reactive analogue azido ruthenium $(\mathrm{AzRu})[162]$ and the lanthanides $\mathrm{La}^{3+}$ and $\mathrm{Tb}^{3+}[160]$ all reduce VDAC1 conductance in the case of native but not mutated VDAC1 [160, 161].

Competition between $\mathrm{Ca}^{2+}$ and RuR [160] suggests that VDAC1 possesses divalent cation-binding site(s). The physiological function of the VDAC1 $\mathrm{Ca}^{2+}$-binding site(s), reflected in the regulation of VDAC1 gating by physiological levels of $\mathrm{Ca}^{2+}$, prolongs a fully open state of the channel, thereby promoting metabolite exchange [156]. Thus, it has become apparent that VDAC1 both mediates $\mathrm{Ca}^{2+}$ transport and is also regulated by $\mathrm{Ca}^{2+}$ binding.

VDAC1 also functions in the $\mathrm{ER} /$ mitochondria- $\mathrm{Ca}^{2+}$ cross-talk. VDAC1 is a constituent of a supra-molecular complex composed of the IP3 receptor in the ER and VDAC1 in the OMM, linked by a chaperone called GRP75 $[13,163]$, together with mitofusin-2 [164, 165].

Thus, by transporting $\mathrm{Ca}^{2+}, \mathrm{VDAC} 1$ plays a fundamental role in regulating mitochondrial $\mathrm{Ca}^{2+}$ homeostasis, oxidative phosphorylation, and $\mathrm{Ca}^{2+}$ crosstalk among mitochondria, cytoplasm, and the ER.

\section{VDAC AND OXIDATIVE STRESS}

Oxidative stress results when production of ROS exceeds the capacity of mitochondrial and cellular anti-oxidant defenses to remove these toxic species. ROS act as second messengers in cell signaling and are essential for multiple biological processes in normal cells. However, ROS are also well known contributors to cell proliferation and cell death [166-169], provoking damage to multiple cellular organelles and processes [170].

Mitochondria are the major source of ROS formation, mostly at complex I (site IQ), complex II (site IIF) and complex III (site IIIQo) [171-173]. $\mathrm{O}_{2} \bullet$ - generated at complex III is released to the cytosol through VDAC1. By contrast, $\mathrm{O}_{2} \bullet$ produced at complexes I and II is released to the matrix, where it is rapidly converted to $\mathrm{H}_{2} \mathrm{O}_{2}$ by superoxide dismutases located in the mitochondrial matrix (MnSOD or SOD2) and the cytosol ( $\mathrm{Cu}, \mathrm{ZnSOD}$ or SOD1) [174]. $\mathrm{H}_{2} \mathrm{O}_{2}$ acts as a cell signaling molecule that does not disrupt redox homeostasis [175] and modulates the pro-survival PI3K/Akt/mTOR HIF-1 and MAP/ERK pathways to promote tumorigenesis and metastasis [176-178]. $\mathrm{H}_{2} \mathrm{O}_{2}$ also forms the highly reactive hydroxyl radical $(\mathrm{OH} \bullet)$ by the Fenton reaction. Whereas both $\mathrm{H}_{2} \mathrm{O}_{2}$ and $\mathrm{O}_{2} \bullet$ - react with mitochondrial and extra-mitochondrial structures, $\mathrm{OH} \bullet$ is so reactive that its effects are almost completely restricted to mitochondria. $\mathrm{O}_{2} \bullet-$ and $\mathrm{OH} \bullet$ can inactivate mitochondrial 
proteins, and damage mitochondrial DNA and lipids in the MIM [179, 180]. Cytosolic ROS also activate members of the MAPK family of serine/threonine kinases, especially the c-Jun N-terminal kinase (JNK), the extracellular signalregulated kinase (ERK 1/2), and p38, whose signaling can cause mitochondrial dysfunction. JNK translocation to $\mathrm{mi}$ tochondria has been shown to cause mitochondrial dysfunction in several models [181, 182].

Cells possess several anti-oxidant defense mechanisms, including the presence of various endogenous molecules, such as glutathione [183-187], or the expression of enzymes like superoxide dismutases (SOD1 and SOD2), catalase, and peroxidase [188]. About $1 \%$ of ROS escape elimination and can be released to the cytosol by crossing the OMM, where they can attack and modify DNA, lipids and proteins affecting cell survival [189].

VDAC1 has been proposed to mediate ROS release from the IMS to the cytosol. This is based on the finding that ROS release from mitochondria was decreased when HK-I and HK-II bound to VDAC1 were over-expressed in HEK cells, reducing intracellular ROS levels [190-192] and protecting against oxidant-induced cell death [190, 193]. In tumor cells, VDAC opening or closing increases or decreases OXPHOS and subsequently increases or decreases ROS generation, respectively. Erastin, a small molecule that antagonizes the inhibitory effect of tubulin on VDAC, increases mitochondrial $\triangle \Psi, \mathrm{NADH}$ and ROS production [85]. Thus, blockage of tubulin-dependent VDAC inhibition works as a pro-oxidant anti-Warburg metabolic switch to promote cancer cell death [88, 194]. By contrast, VDAC1 closure by DIDS and dextran sulfate inhibits the efflux of $\mathrm{O}_{2}-\bullet$ to the cytosol and increases the steady-state level of $\mathrm{O}_{2} \bullet-$, sensitizing mitochondria to $\mathrm{Ca}^{2+}$-induced MPT [195].

Cysteine residues, often involved in redox reactions, metal coordination and thiol-disulfide interchanges, are extremely vulnerable to oxidation by ROS. VDAC has been proposed to function in physiological redox regulation via the modification of the sulfhydryl groups of VDAC [196]. In humans, VDAC1 contains two cysteines, VDAC2 contains nine cysteines and VDAC3 contains six cysteines, all of which are predicted to protrude towards the IMS and can be subjected to oxidation by ROS [4]. We have shown that for VDAC1, deletion of both cysteines does not affect channel conductance, VDAC1 oligomerization or apoptosis [53]. Cysteines contribute to the folding, function and stability of hVDAC2. VDAC3 was found to be the target of mitochondrial ROS specifically generated by complex III and was proposed to act as a sensor of the oxidative state of the IMS via cysteine residue modification [197].

Accumulating evidence indicates that ROS play a key role in Cyto $c$ release from mitochondria and that this involves VDAC1. Apoptosis-inducing agents, such as inorganic arsenic compounds [198, 199] and doxorubicin [200], induce apoptosis by inducing ROS generation. The inhibition of $\mathrm{O}_{2}-\bullet$-induced apoptosis by DIDS, an inhibitor of VDAC channel activity, or by anti-VDAC1 antibodies [12, $129,201]$, suggests that $\mathrm{O}_{2}-\bullet$ induces Cyto $c$ release via VDAC1-dependent permeabilization of the OMM [129]. Moreover, $\mathrm{O}_{2}-\bullet$ was found to evoke Cyto $c$ release in
VDAC1-reconstituted liposomes [129]. In other studies, it was found that ROS-induced alterations of VDAC1 and/or ANT could make the PTP selective for Cyto $c$ release, without causing further mitochondrial damage [129, 202]. Moreover, it was shown that ROS induced up-regulation of VDAC1 that could be prevented by the ROS chelator, epigallocatechin [144]. It has been suggested that ROSmediated Cyto $c$ and SOD1 release from mitochondria involves VDAC, leading to increased susceptibility of mitochondria to oxidative stress and apoptosis [203].

VDAC is also affected by hypoxic conditions shown to induce cleavage at the $\mathrm{C}$-terminal end of the protein (VDAC1- $\triangle C$ ), with such cleavage being prevented upon silencing of HIF-1 $\alpha$ expression [204, 205]. It was proposed that hypoxia, by inducing formation of VDAC1- $\triangle C$, confers selective protection from apoptosis that allows maintenance of ATP and cell survival in hypoxia [206].

\section{VDAC1 AS A HUB PROTEIN - MODULATION OF VDAC1- MEDIATED APOPTOSIS AND METABOLISM VIA INTERACTING PROTEINS}

As presented above, VDAC1 is crucial for many cellular processes, including metabolism, $\mathrm{Ca}^{2+}$ homeostasis, apoptosis, and other activities regulated via the interaction of VDAC1 with many proteins associated with cell survival and cellular death pathways [1, 29-31]. Indeed, VDAC1 is considered as a hub protein, interacting with over 100 proteins that regulate the integration of mitochondrial functions with other cellular activities [207]. VDAC1 serves as an anchor protein for diverse sets of cytosolic, ER, and mitochondrial proteins $[12,208]$ that together regulate metabolic and signaling pathways, provide energy for cellular functions, or trigger cell death. Thus, VDAC1 appears to be a convergence point for a variety of cell survival and death signals, mediated via association with ligands and proteins.

In support of this viewpoint, the conserved nature of VDAC1 [1] is in agreement with the finding that hub proteins are more evolutionarily conserved than are non-hub proteins [209]. VDAC1 protein-protein interaction (PPI) networks contain both hub-bottlenecks [210] (namely nodes with high degree values constituting vulnerable areas of the network) and/or bottlenecks (those with high "betweenness" centrality scores, corresponding to key intersecting nodes [211]). The VDAC1 interactome includes proteins involved in metabolism, apoptosis, signal transduction, anti-oxidation, and DNA- and RNA-associated proteins and more (Supplemental Table S1) [1, 29, 31, 32]. Furthermore, these proteins may be located in the OMM, IMM, the IMS, the cytosol, ER, plasma membrane, and nucleus. Importantly, we have been able to develop VDAC1-based peptides which can interfere with these in teractions, leading to impaired cell metabolism and apoptosis [25-27, 212, 213].

\section{Interactions of VDAC1 with metabolism-related proteins}

VDAC1 displays binding sites for a large number of metabolism-related proteins, such as glycerol kinase (GK), HK, c-Raf kinase, ANT, tubulin, $[1,29-31]$ and the glycolytic enzyme GAPDH (glyceraldehyde 3-phosphate dehydrogenase) [214]. 
Mitochondrial creatine kinase (MtCK), in its octameric state, interacts with VDAC1 [35] and causes decreased affinity of VDAC1 for HK and Bax [215] (Supplemental Table S1). HK binding to VDAC1 $[25,104,118,122,124,216]$ allows direct coupling of mitochondrially generated ATP to glucose phosphorylation. Thus, the formation of a VDAC1-HK complex coordinates glycolytic flux with the actions of the TCA cycle and ATP synthase $[1,33,81]$.

The OMM protein CPT1a that catalyzes the primary step of fatty acid oxidation interacts with VDAC1 [65]. Another OMM protein interacting with VDAC1 is the TSPO, involved in the transport of cholesterol into mitochondria [217]. Aldolase, involved in gluconeogenesis and glycolysis, was also shown to interact with VDAC1 [17].

\section{Interactions of VDAC1 with apoptosis-related proteins}

The Bcl-2 family comprises pro-apoptotic (e.g. Bid, Bax, Bim and Bak) and anti-apoptotic (e.g. Bcl-2 and $\mathrm{Bcl}-\mathrm{xL}$ ) members that up- or down-regulate apoptosis, respectively [218, 219]. VDAC1 function in apoptosis can be regulated by interactions with anti-apoptotic proteins, such as Bcl2 and Bcl-xL [23, 25, $26,117,220-223]$, resulting in inhibition of apoptotic pathways. $\mathrm{Bcl}-2$ and $\mathrm{Bcl}-\mathrm{xL}$ were shown to interact with bilayerreconstituted VDAC1 and subsequently to reduce the channel conductance of native but not mutated VDAC1, as well as to protect against apoptosis in cells expressing native but not mutated VDAC1 $[25,26]$. The VDAC1 domains that interact with $\mathrm{Bcl}-2$ and $\mathrm{Bcl}-\mathrm{xL}$ to confer anti-apoptotic activity were identified by site-directed mutagenesis [25]. Mcl-1 has been shown to directly interact with VDAC to increase mitochondrial $\mathrm{Ca}^{2+}$ uptake and ROS generation [224]. The HK-VDAC interaction also prevents release of pro-apoptotic factors, such as Cyto $c$, and subsequent apoptosis. Thus, HK plays a role in tumor cell survival via inhibition of apoptosis [118]. The interaction between TSPO and VDAC is considered to play a role in the activation of the mitochondrial apoptosis pathway, given the reported grouping of TSPO molecules around VDAC, potentially reflecting TSPO polymerization [225], and the increased ROS generation by TSPO in the proximity of VDAC, leading to apoptosis induction [225, 226]. Nek1 (NIMA-related protein kinase 1) phosphorylates VDAC1 on serine 193, with this leading to apoptosis inhibition $[146,227]$. Finally, the proapoptotic protein BNIP3 was shown to interact with VDAC so as to induce mitochondrial release of endonuclease G [228].

\section{Interactions of VDAC1 with cytoskeletal proteins}

VDAC1 interacts with several cytoskeletal proteins, such as gelsolin (Gsn), with this interaction resulting in inhibited VDAC1 channel activity and Cyto $c$ release from liposomes through direct binding to VDAC1 in a $\mathrm{Ca}^{2+}$-dependent manner $[229,230]$. Tubulin was shown to associate with VDAC1 [231] and induce VDAC1 closure [86], proposed to sustain the Warburg effect [232]. It was further proposed that tubulin, VDAC1, and MtCK form a super-complex that is structurally and functionally coupled to the ATP synthasome [233]. G-actin directly and selectively binds to VDAC in yeast, [234], reducing conductance of the Neurospora crassa VDAC channel [235]. Microtubule-associated protein 2 (MAP2) was shown to bind VDAC [236]. The interaction of VDAC1 with Tctex-1/DYNLT1 (dynein light chain) was also demonstrated [237].

\section{Interactions of VDAC1 with signaling proteins}

Superoxide dismutase 1 (SOD1) is a predominantly cytosolic protein, with mutant SOD1 being present mostly in fractions enriched for mitochondria [238-240]. Mutant SOD1 associated with amyotrophic lateral sclerosis (ALS) bound to bilayerreconstituted VDAC1 and inhibited its channel conductance [241]. Mutant SOD1 also interacted with Bcl2 protein and altered the interaction between $\mathrm{Bcl}-2$ and VDAC1, thus reducing OMM permeability [242].

Endothelial NO synthase (eNOS) was also found to bind VDAC1. Such interactions amplified eNOS activity in an intracellular $\mathrm{Ca}^{2+}$-mediated manner [243]. These findings suggest that the interaction between VDAC and eNOS may be important for regulating eNOS activity and modulation of VDAC [243].

The mitochondrial anti-viral signaling protein MAVS, also known as IPS-1, VISA, or Cardif [244], and localized in the OMM, was demonstrated to mediate its pro-apoptotic activity via VDAC1 and to modulate VDAC1 protein stability via the ubiquitin-proteasome pathway [245]. VDAC was further proposed to interact with the L-type $\mathrm{Ca}^{2+}$ channel [246].

Several additional proteins were shown or proposed to directly interact with VDAC1 (Supplemental Table S1). These include PBP74, also known as mtHSP70/GRP75/mortalin [237], CRYAB ( $\alpha$-crystallin B) [247] and $\alpha$-synuclein [248]. VDAC1interacting protein complexes mediate and/or regulate metabolic, apoptotic, and other processes that may be impaired in disease.

\section{VDAC INVOLVEMENT IN DISEASE}

Mitochondria occupy a central position in cell life and death and mitochondrial dysfunction has been implicated in many diseases, including cancer, Alzheimer's disease (AD), Parkinson's disease (PD), amyotrophic lateral sclerosis (ALS), diabetes, and cardiovascular diseases (CVDs). VDAC1 functions as mitochondria gatekeeper that regulates ATP production, $\mathrm{Ca}^{2+}$ homeostasis and apoptosis execution, all indispensable for proper mitochondrial function, and consequently, for cell normal physiology. Thus, the association of VDAC with various diseases is not surprising. Furthermore, VDAC over-expression is a common feature of cancer, $A D$, type 2 diabetes (T2D) and CVDs. The overexpression of VDAC1 in cancer $[54,59]$, in affected regions of AD brains [97-99], in $\beta$-cells of T2D [101] and in CVDs [250], is a feature common to these diseases. As VDAC1 over-expression induces apoptotic cell death $[58,113,119$, $120,122]$, its over-expression in CVDs, AD and T2D, may be a common mechanism in these pathologies.

\section{The cancer-mitochondria-metabolism-apoptosis-VDAC1 link}

Cancer is a complex disease in which cells acquire a common set of properties, including unlimited proliferation, metabolic reprograming, and resistance to anti-proliferative and apoptotic cues $[78,250]$. Emerging evidence indicates that metabolic reprogramming, which supports macromolecule synthesis, bioenergetics demands, and cellular survival is a characteristic of nearly all cancers $[68,251]$. Over the years, Otto Warburg's view of cancer as a metabolic disease was gradually displaced with the view of cancer as a genetic disease [252]. Today, however, cancer is again being seen as a metabolic 
disease, primarily associated with impaired mitochondrial function and metabolism $[75,79]$.

VDAC1 is highly expressed in different tumors [54, 59], contributing to their metabolism via the transport of various metabolites, and the binding and channeling of mitochondrial ATP directly to HK [5]. This results in mitochondria regulating glycolytic flux with that actions of the TCA cycle and ATP synthase to fulfill the requirements of tumors for metabolites or metabolite precursors. Indeed, tumors switch their HK expression pattern predominantly to present the VDAC1-binding isoforms (HK-I, HK-II) [253]. The requirement of cancer cells for VDAC1 is demonstrated by down-regulation of VDAC1, resulting in reduced metabolite exchange between mitochondria and cytosol and inhibition of cell and tumor growth [32, $58,59,90,91]$.

VDAC1 also regulates apoptosis in cancer cells by interacting with the anti-apoptotic proteins $\mathrm{Bcl}-2$ and $\mathrm{Bcl}-\mathrm{xL}[23,25$, $26,254]$ and HK $[23,27]$, interactions that protect tumor cells from cell death [23, 27]. Thus, activating mitochondriamediated apoptosis directly or via generating stress responses [255-257] is a strategy to treat cancer. Indeed, a large number of anti-cancer chemotherapeutic agents exert their therapeutic action by inducing apoptosis of malignant cells [258-263], mainly by activating the Cyto $c /$ caspase- 9 pathway. These include etoposide, doxorubicin, lonidamine, betulinic acid, arsenite, CD437, and several amphiphilic cationic $\alpha$-helical peptides [264]. Therefore, targeted activation of apoptosis in cancerous tissues may be exploited as a potential route to cancer therapy [265]. However, they do not act on cancer stem cells (CSCS), which are resistant to chemo- and radiotherapies [266-268]. The CSC hypothesis postulates that a subpopulation of malignant cells constantly supply the tumor with cancerous cells. CSCs, as embryonic and somatic stem cells, have self-renewal and multi-potent differentiation abilities $[269,270]$. Recent studies from the Shoshan-Barmatz group $[91,213]$ have demonstrated novel strategies for eliminating CSCs.

Regulation of VDAC1 expression by miRNA was demonstrated in several studies. In serum-starved cervical cancer cells, miR320a promoted mitophagy [93], while ectopic overexpression of miR320a blocked tumor cell proliferation and invasion in NSCLC, both in vitro and in vivo [271]. Another miRNA species, miR-7, was shown to inhibit VDAC1 expression, proliferation and metastasis in hepatocellular carcinoma [94], possibly by affecting the PTP [95].

Thus, the importance of VDAC1 for cancer cell survival is clearly reflected in the above findings, with silencing VDAC1 expression in cancer cells resulting in a multi-pronged attack on cancer hallmarks.

\section{Neurodegenerative diseases, mitochondria, apoptosis, and VDAC}

There is emerging evidence connecting mitochondrial dysfunction to neurodegenerative disorders [169]. In PD, Huntington's disease (HD), ALS and $A D$, impaired mitochondrial function has been reported [272], with a focus on the involvement of mitochondria-mediated apoptotic death [273]. Mitochondrial dysfunction was proposed as an early event in $A D$ pathogenesis, as reflected in reduced metabolism, increased ROS, lipid peroxidation and disruption of $\mathrm{Ca}^{2+}$-homeostasis, [274-276]. Moreover, mitochondria-mediated apoptosis is common to neurological disorders in which premature neuron death is implicated [273, 277, 278], with caspases playing dominant roles [279-281]. Amyloid beta $(A \beta)$ also affects mitochondrial respiration [282] and activates Cyto $c$ release, thereby promoting apoptosis [283].

Several studies suggested that VDAC malfunction is associated with AD [284-287], Down's syndrome [287], and familial ALS [241, 288]. High levels of VDAC1 were demonstrated in the dystrophic neurites of $A \beta$ deposits in post-mortem brains of $A D$ patients and in amyloid precursor protein (APP) transgenic mice, where $A \beta$-VDAC interactions are toxic to $A D$ affected neurons [97, 98, 286, 287, 289-291]. The expression of hVDAC-2 was shown to be associated with neurodegenerative diseases, including ALS [288], epilepsy [292], and AD [286].

As VDAC1 over-expression was shown to lead to apoptotic cell death $[58,113,119,120,122]$ and high-levels of VDAC1 were found in the dystrophic neurites of $A \beta$ deposits in $A D$ post-mortem brains and APP transgenic mice [97-99], we propose that over-expressed VDAC is associated with neuronal cell death [291]

We have demonstrated that $A \beta$ interacts directly with VDAC1, specifically with the VDAC1 N-terminal region and that VDAC1 is required for $A \beta$ entry into the cell, as well as for $A \beta$ mediated apoptosis, with $A \beta$ cell penetration and toxicity being prevented in cells depleted of VDAC1 by siRNA [291]. VDAC was also shown to interact with phosphorylated Tau, leading to mitochondrial dysfunction [290]. In addition, an increase in nitrated VDAC1 levels in AD was reported, reflecting oxidative damage to VDAC [293], and possibly affecting cell energy and metabolite homeostasis [284]. The involvement of plasmalemmal VDAC in AD was also proposed $[285,289]$.

The relationship between VDAC1 expression levels and neurodegenerative disorders is also reflected in the finding that in patients and animal models of several neurodegenerative disorders, such as $A D, H D$, and spinocerebellar ataxias, miR-29a expression levels were reduced [294]. miR-29a was also shown to regulate cell survival of astrocytes differentially by targeting VDAC1 [295]. These findings suggest that VDAC1 down-regulation by miR-29 is an important aspect of neuronal cell survival in the brain [294]. As VDAC1 over-expression triggers apoptosis [120-122], and high-levels of VDAC1 were demonstrated in $A D$ post-mortem brains and in $A D$-like transgenic mice [99], the reported decrease in miR-29a in AD [294] may be associated with neuronal cell death. Indeed, miR320a-mediated down-regulation of VDAC1 expression has been proposed as a novel therapeutic target for astrogliamediated HIV-1 neuropathogenesis [296].

Finally, several proteins interacting with VDAC, such as SOD1, $\alpha$-synuclein and ApoE, were proposed to be involved in several neurodegenerative diseases, affecting intraneuronal $\mathrm{Ca}^{2+}[155]$. These findings point to VDAC1 as a potential target for novel therapeutic strategies for neurodegenerative diseases.

\section{T2D, metabolism, mitochondria and VDAC1}

T2D is the most common metabolic disease [297]. Defective insulin secretion, insulin resistance at target tissues and a loss of functional $\beta$-cells contribute to T2D, and dysregulation of glucose homeostasis [298]. Recently, it has been shown that hyperglycemia increases VDAC1 expression in pancreatic $\beta$ cells [101] and in the kidney [102]. VDAC1 levels were increased in mouse coronary vascular endothelial cells (MCECs) isolated from diabetic mice. This was associated with in- 
creased $\left[\mathrm{Ca}^{2+}\right] \mathrm{m}, \mathrm{O}_{2}$ production, and PTP opening activity [299] Down-regulation of VDAC1 in diabetic MCECs decreased $\left[\mathrm{Ca}^{2+}\right] \mathrm{m}$ and subsequently affected PTP activity and ROS production [300]. As glucose-stimulated insulin secretion depends on the generation of ATP and other metabolites in the mitochondria [301], and VDAC1 regulates energy and metabolism, VDAC1 is thus required for insulin secretion. Recently, IncRNAH19/miR-675 was reported to regulate high glucose-induced apoptosis by targeting VDAC1, and thus provides a novel therapeutic strategy for the treatment of diabetic cardiomyopathy [96]. These findings point to the connection between VDAC, mitochondrial function and the pathogenesis of T2D.

\section{Cardiovascular diseases, mitochondria, apoptosis and VDAC}

It is known that most CVDs evolve into heart failure and that the loss of cardiac myocytes plays a critical role in the pathogenesis of CVDs. Activation of mitochondria-mediated apoptosis has been implicated in ischemia/reperfusion injury [302]. VDAC levels were increased in cardiomyoblast H9c2 cells [249] As VDAC1 over-expression is associated with apoptosis [58, $113,119,120,122]$, it is possible that increased cardiomyocyte susceptibility to mitochondrial-mediated cell death is related to the increase in VDAC1 levels. Indeed, the effect of resveratrol against myocardial ischemia/reperfusion injury showed involvement of VDAC1 down-regulation [100].

The findings presented above suggest that modulating VDAC1 expression levels or its apoptotic activity are possible strategies to either activate apoptosis in cancer or inhibit apoptosis in CVDs, AD and T2D.

\section{UNRAVELING VDAC1-BASED THERAPIES}

VDAC1-based strategies are expected to be effective in various diseases characterized by altered cell metabolism and/or apoptosis and by VDAC1 over-expression. As VDAC1 over-expression induces apoptotic cell death [58, 113, 119, $120,122]$, we suggest that this may be a common mechanism in the pathology of CVDs, AD and T2D. Modulating VDAC1 expression levels or its apoptotic activity are possible strategies to either activate apoptosis in cancer or inhibit apoptosis in CVDs, AD and T2D. In this review, VDAC1based therapeutic strategies targeting tumor cells are presented. These cancer therapy strategies include siRNA altering the normal functioning of cancer cells, leading to growth arrest, and VDAC1-based peptides that impair energy homeostasis and minimize the self-defense mechanisms of these cells, and that can be used to overcome protective and pro-survival actions taken by cancer cells.

\section{VDAC1-depletion using RNAi}

Specifically targeting metabolism in cancer cells presents a potential therapeutic strategy. However, although glucose metabolism is increased in cancer cells, these cells mostly use the same glycolytic enzymes as do normal cells, so that the choice of glycolytic enzymes as targets for cancer treatment may increase the risk of adverse and undesirable consequences [303]. Targeting VDAC1, acting as a 'governor' of mitochondrial function, regulating cellular energy and metabolism, and over-expressed in cancer, offers a unique target for anticancer therapies. Down-regulation of VDAC1 addresses the cancer trademark of cell metabolic and energy reprogramming, leading to disrupted cancer cell energy and metabolism homeostasis.

VDAC1 depletion using specific siRNA (si-VDAC1) led to reduced cellular ATP levels and inhibited cell and tumor growth in cervical and lung cancers [58, 59, 90]. Using a subcutaneous and intracranial-orthotopic GBM model, we found that VDAC1 depletion resulted in inhibited tumor growth, with the residual tumor showing reversed oncogenic properties, including metabolic reprograming and inhibited proliferation, angiogenesis, EMT, invasiveness and stemness, leading to differentiation into neuron- and astrocyte-like cells [91] (Fig. 4).

\section{VDAC1-based peptides as potential anti-cancer therapy}

A hallmark of cancer cells is their ability to suppress proapoptotic pathways and/or to activate anti-apoptotic mechanisms $[78,250]$ associated with drug resistance [304], such as the $\mathrm{Bcl}-2$ family of proteins and $\mathrm{HK}$, preventing the release of Cyto $c$ from mitochondria. Since the anti-apoptotic proteins HK-I, HK-II, BCl2 and BCl-xL have been found to be expressed at high levels in many types of cancer [81, 253, 305-310] and interact with VDAC1 $[1,22,23-27,81,82,84,118,122,124$, $128,220,311,312]$, the interaction of VDAC1with these proteins is proposed as an appropriate target to induce apoptosis.

We have engineered VDAC1-based peptides that interfere with the activity of the pro-survival proteins $\mathrm{BCl}-2, \mathrm{BCl}-\mathrm{xL}$ and HK $[23,25-27,118,122,212]$. Via point mutations, VDAC1 domains and amino acid residues important for interactions with $\mathrm{HK}, \mathrm{Bcl}-2$ and $\mathrm{Bcl}-\mathrm{xL}$ were identified and cell-penetrating VDAC1-based peptides targeting these interactions were designed and tested [23, 25-27, 118, 122]. These VDAC1-based peptides were found to induce cancer cell death in a panel of genetically characterized cancer cell lines, regardless of cancer type or mutation status, with perceived specificity toward cancerous cells $[23,27,212]$. Studies demonstrated a triple mode of action, namely energy and metabolism impairment, interference with the action of anti-apoptotic proteins, and a triggering of cell death.

In an ex vivo study, cell-penetrating VDAC1-based peptides were found to induce apoptotic cell death in the cancerous Bcells of peripheral blood mononuclear cells obtained from chronic lymphocytic leukemia (CLL) patients, yet spared those obtained from healthy donors, pointing to the potential of VDAC1-based peptides as an innovative and effective anti-CLL therapy.

In a GBM mouse model, i.v.-administered VDAC1-based peptide Tf-D-LP4 crossed the blood-brain barrier and was found to inhibit tumor growth by inducing apoptosis and overexpression of apoptotic proteins [213]. Such treatment simultaneously attacked several cancer hallmarks, causing impairment of energy and metabolic homeostasis, inhibition of tumor growth and induction of apoptosis. VDAC1-based peptides, expecting to also affect other cancers, provide the opportunity for the development of new anti-cancer therapies that will allow overcoming the chemo-resistance of cancer cells.

In summary, VDAC1 functions in ATP production and metabolism, $\mathrm{Ca}^{2+}$ homeostasis and apoptosis execution are indispensable for proper mitochondrial function of cancer cell, and consequently, for cell activity. These VDAC-mediated activities are regulated via interactions of VDAC1 with many proteins that are critically involved in the regulation of cell survival and 
cellular death pathways. VDAC1, standing at the crossroads between mitochondrial-mediated energy and metabolism and apoptosis, is a potential target for treating cancer and other diseases involving dysregulated metabolism and/or apoptosis and where VDAC1 is over-expressed. Thus, a new generation of VDAC1-based therapeutics may impact the treatment of a variety of diseases.

To conclude, the dysregulated cell stress response involves mitochondria dysfunction and this play a critical role in tumorigenesis, and other disease, such as Alzheimer's disease, some cardiovascular disease and type 2 diabetes. The role of VDAC1 in $\mathrm{Ca}^{2+}$ homeostasis, energy production and oxidative stress, and with VDAC1 serving as a hub protein interacting with over 100 proteins allow it to mediate and regulate the integration of mitochondrial functions with cellular activities. Thus, VDAC1, standing at the crossroads between mitochondrial metabolite transport, apoptosis and other cell stress-associated processes, serves as the mitochondrial gatekeeper. This, together with its over-expression in cancer and other diseases, including Alzheimer's disease, some cardiovascular diseases and type 2 diabetes, involves VDAC1 in the cell stress response and thus represents a target to modulate the biology of cancer and other diseases.

\section{ACKNOWLEDGMENTS}

This research was supported by grants from the Israel Science Foundation (307/13), by Ezra and Yafa Yeruham and Sima and Philip Needleman research funds to VSB, and R01CA184456 (NCI), COBRE Project GM103542 and ACS 13-041-01-IRG funding to ENM.

\section{SUPPLEMENTAL MATERIAL}

All supplemental data for this article are available online at www.cell-stress.com.

\section{CONFLICT OF INTEREST}

The authors declare no conflict of interest.

\section{COPYRIGHT}

(C) 2017 Shoshan-Barmatz et al. This is an open-access article released under the terms of the Creative Commons Attribution (CC BY) license, which allows the unrestricted use, distribution, and reproduction in any medium, provided the original author and source are acknowledged.

Please cite this article as: Varda Shoshan-Barmatz, Eduardo N. Maldonado and Yakov Krelin (2017). VDAC1 at the crossroads of cell metabolism, apoptosis and cell stress. Cell Stress 1(1): 11-36. doi: $10.15698 /$ cst2017.10.104

lacking mitochondrial voltage-dependent anion channel type 3. J Biol Chem 276(42): 39206-39212. doi: 10.1074/jbc.M104724200

9. Weeber EJ, Levy M, Sampson MJ, Anflous K, Armstrong DL, Brown SE, Sweatt JD, Craigen WJ (2002). The role of mitochondrial porins and the permeability transition pore in learning and synaptic plasticity. J Biol Chem 277(21): 18891-18897. doi: 10.1074/jbc.M201649200

10. Bathori G, Parolini I, Szabo I, Tombola F, Messina A, Oliva M, Sargiacomo M, De Pinto V, Zoratti M (2000). Extramitochondrial porin facts and hypotheses. J Bioenerg Biomembr 32(1): 79-89. doi: doi:10.1023/A:1005516513313

11. Bathori G, Parolini I, Tombola F, Szabo I, Messina A, Oliva M, De Pinto V, Lisanti M, Sargiacomo M, Zoratti M (1999). Porin is present in the plasma membrane where it is concentrated in caveolae and caveolae-related domains. J Biol Chem 274(42): 29607-29612. doi.: 10.1074/jbc.274.42.29607

12. Shoshan-Barmatz V, Hadad N, Feng W, Shafir I, Orr I, Varsanyi M, Heilmeyer LM (1996). VDAC/porin is present in sarcoplasmic reticulum from skeletal muscle. FEBS Lett 386(2-3): 205-210. doi: 10.1016/00145793(96)00442-5

13. Shoshan-Barmatz V, Zalk R, Gincel D, Vardi N (2004). Subcellular localization of VDAC in mitochondria and ER in the cerebellum. Biochim Biophys Acta 1657(2-3): 105-114. doi: 10.1016/j.bbabio.2004.02.009

14. Sabirov RZ, Merzlyak PG (2012). Plasmalemmal VDAC controversies and maxi-anion channel puzzle. Biochim Biophys Acta 1818(6): 1570-1580. doi: 10.1016/j.bbamem.2011.09.024 
15. Buettner R, Papoutsoglou G, Scemes E, Spray DC, Dermietzel R (2000). Evidence for secretory pathway localization of a voltagedependent anion channel isoform. Proc Natl Acad Sci U S A 97(7): 3201-3206. doi: 10.1073/pnas.060242297

16. Thinnes FP, Gotz H, Kayser H, Benz R, Schmidt WE, Kratzin HD, Hilschmann N (1989). Identification of human porins. I. Purification of a porin from human B-lymphocytes (Porin $31 \mathrm{HL}$ ) and the topochemical proof of its expression on the plasmalemma of the progenitor cell. Biol Chem Hoppe Seyler 370(12): 1253-1264. PMID: 2559744

17. Shoshan-Barmatz V, Israelson A (2005). The voltage-dependent anion channel in endoplasmic/sarcoplasmic reticulum: characterization, modulation and possible function. J Membr Biol 204(2): 57-66. doi: 10.1007/s00232-005-0749-4

18. Bayrhuber $M$, Meins $T$, Habeck $M$, Becker S, Giller K, Villinger $S$, Vonrhein C, Griesinger C, Zweckstetter M, Zeth K (2008). Structure of the human voltage-dependent anion channel. Proc Natl Acad Sci U S A 105(40): 15370-15375. doi: 10.1073/pnas.0808115105

19. Hiller S, Garces RG, Malia TJ ,Orekhov VY, Colombini M, Wagner G (2008). Solution structure of the integral human membrane protein VDAC-1 in detergent micelles. Science 321(5893): 1206-1210. doi: 10.1126/science. 1161302

20. Ujwal R, Cascio D, Colletier JP, Faham S, Zhang J, Toro L, Ping P, Abramson J (2008). The crystal structure of mouse VDAC1 at $2.3 \mathrm{~A}$ resolution reveals mechanistic insights into metabolite gating. Proc Natl Acad Sci U S A 105(46): 17742-17747. doi: 10.1073/pnas.0809634105

21. Hiller S, Wagner G (2009). The role of solution NMR in the structure determinations of VDAC-1 and other membrane proteins. Curr Opin Struct Biol 19(4): 396-401. doi: 10.1016/j.sbi.2009.07.013

22. Geula S, Ben-Hail D, Shoshan-Barmatz V (2012). Structure-based analysis of VDAC1: N-terminus location, translocation, channel gating and association with anti-apoptotic proteins. Biochem J 444(3): 475485. doi: 10.1042/BJ20112079

23. Abu-Hamad S, Arbel N, Calo D, Arzoine L, Israelson A, Keinan N, Ben-Romano R, Friedman O, Shoshan-Barmatz V (2009). The VDAC1 $\mathrm{N}$-terminus is essential both for apoptosis and the protective effect of anti-apoptotic proteins. J Cell Sci 122(Pt 11): 1906-1916. doi: $10.1242 /$ jcs.040188

24. Shi Y, Chen J, Weng C, Chen R, Zheng Y, Chen Q, Tang H (2003). Identification of the protein-protein contact site and interaction mode of human VDAC1 with Bcl-2 family proteins. Biochem Biophys Res Commun 305(4): 989-996. doi: 10.1016/S0006-291X(03)00871-4

25. Arbel N, Ben-Hail D, Shoshan-Barmatz V (2012). Mediation of the antiapoptotic activity of $\mathrm{Bcl}-\mathrm{xL}$ protein upon interaction with VDAC1 protein. J Biol Chem 287(27): 23152-23161. doi: 10.1074/jbc.M112.345918

26. Arbel N, Shoshan-Barmatz V (2010). Voltage-dependent anion channel 1-based peptides interact with $\mathrm{Bcl}-2$ to prevent antiapoptotic activity. J Biol Chem 285(9): 6053-6062. doi: 10.1074/jbc.M109.082990

27. Arzoine L, Zilberberg N, Ben-Romano R, Shoshan-Barmatz V (2009). Voltage-dependent anion channel 1-based peptides interact with hexokinase to prevent its anti-apoptotic activity. J Biol Chem 284(6): 3946-3955. doi: 10.1074/jbc.M803614200
28. Keinan N, Tyomkin D, Shoshan-Barmatz V (2010). Oligomerization of the mitochondrial protein voltage-dependent anion channel is coupled to the induction of apoptosis. Mol Cell Biol 30(24): 56985709. doi: 10.1128/MCB.00165-10

29. Shoshan-Barmatz V, Israelson A, Brdiczka D, Sheu SS (2006). The voltage-dependent anion channel (VDAC): function in intracellular signalling, cell life and cell death. Curr Pharm Des 12(18): 2249-2270. doi: $10.2174 / 138161206777585111$

30. Shoshan-Barmatz V, Mizrachi D (2012). VDAC1: from structure to cancer therapy. Front Oncol 2:164. doi: 10.3389/fonc.2012.00164

31. Shoshan-Barmatz V, Mizrachi D, Keinan N (2013). Oligomerization of the mitochondrial protein VDAC1: from structure to function and cancer therapy. Prog Mol Biol Transl Sci 117:303-334. doi: 10.1016/B978-0-12-386931-9.00011-8

32. Shoshan-Barmatz V, Golan M (2012). Mitochondrial VDAC1: function in cell life and death and a target for cancer therapy. Curr Med Chem 19(5): 714-735. doi: 10.2174/092986712798992110

33. Shoshan-Barmatz V, Keinan N, Zaid H (2008). Uncovering the role of VDAC in the regulation of cell life and death. J Bioenerg Biomembr 40(3): 183-191. doi: 10.1007/s10863-008-9147-9

34. Zeth K, Meins T, Vonrhein C (2008). Approaching the structure of human VDAC1, a key molecule in mitochondrial cross-talk. J Bioenerg Biomembr 40(3): 127-132. doi: 10.1007/s10863-008-9144-z

35. Schlattner U, Tokarska-Schlattner M, Wallimann T (2006). Mitochondrial creatine kinase in human health and disease. Biochim Biophys Acta 1762(2): 164-180. doi: 10.10/16j.bbadis.2005.09.004

36. Zalk R, Israelson A, Garty ES, Azoulay-Zohar H, Shoshan-Barmatz V (2005). Oligomeric states of the voltage-dependent anion channel and cytochrome c release from mitochondria. Biochem J 386(Pt 1): 73-83. doi: 10.1042/BJ20041356

37. Geula S, Naveed H, Liang J, Shoshan-Barmatz V (2012). Structurebased analysis of VDAC1 protein: defining oligomer contact sites. J Biol Chem 287(3): 2179-2190. doi: 10.1074/jbc.M111.268920

38. Ujwal R, Cascio D, Chaptal V, Ping P, Abramson J (2009). Crystal packing analysis of murine VDAC1 crystals in a lipidic environment reveals novel insights on oligomerization and orientation. Channels (Austin) 3(3): 167-170. doi: 10.4161/chan.3.3.9196

39. Schlattner U, Dolder M, Wallimann T, Tokarska-Schlattner M (2001). Mitochondrial creatine kinase and mitochondrial outer membrane porin show a direct interaction that is modulated by calcium. J Biol Chem 276(51): 48027-48030. doi: 10.1074/jbc.M106524200

40. Ben-Hail D, Shoshan-Barmatz V (2014). Purification of VDAC1 from rat liver mitochondria. Cold Spring Harb Protoc 2014(1): 94-99. doi: 10.1101/pdb.prot073130

41. Gincel D, Silberberg SD, Shoshan-Barmatz V (2000). Modulation of the Voltage-Dependent Anion Channel (VDAC) by Glutamate1. J Bioenerg Biomembr 32(6): 571-583. doi: 10.1023/A:1005670527340

42. Colombini M (2012). VDAC structure, selectivity, and dynamics. Biochim Biophys Acta 1818(6): 1457-1465. doi: 10.1016/j.bbamem.2011.12026.

43. Rostovtseva T, Colombini M (1997). VDAC channels mediate and gate the flow of ATP: implications for the regulation of mitochondrial 
function. Biophys J 72(5): 1954-1962. doi: 10.1016/S00063495(97)78841-6

44. Gincel D, Shoshan-Barmatz V (2004). Glutamate interacts with VDAC and modulates opening of the mitochondrial permeability transition pore. J Bioenerg Biomembr 36(2): 179-186. doi: 10.1023/B:JOBB.0000023621.72873.9e

45. Rostovtseva TK, Komarov A, Bezrukov SM, Colombini M (2002). VDAC channels differentiate between natural metabolites and synthetic molecules. J Membr Biol 187(2): 147-156. doi: 10.1007/s00232001-0159-1

46. Yehezkel G, Hadad N, Zaid H, Sivan S, Shoshan-Barmatz V (2006). Nucleotide-binding sites in the voltage-dependent anion channel: characterization and localization. J Biol Chem 281(9): 5938-5946. doi: 10.1074/jbc.M510104200

47. Shoshan-Barmatz V, Gincel D (2003). The voltage-dependent anion channel: characterization, modulation, and role in mitochondrial function in cell life and death. Cell Biochem Biophys 39(3): 279-292. doi: 10.1385/CBB:39:3:279

48. Bera AK, Ghosh S, Das S (1995). Mitochondrial VDAC can be phosphorylated by cyclic AMP-dependent protein kinase. Biochem Biophys Res Commun 209(1): 213-217. doi: 10.1006/bbrc.1995.1491

49. Baines $C P$, Song $C X$, Zheng YT, Wang GW, Zhang J, Wang OL, Guo Y, Bolli R, Cardwell EM, Ping P (2003). Protein kinase Cepsilon interacts with and inhibits the permeability transition pore in cardiac mitochondria. Circ Res 92(8): 873-880. doi: 10.1161/01.RES.0000069215.36389.8D

50. Liberatori S, Canas B, Tani C, Bini L, Buonocore G, GodovacZimmermann J, Mishra OP, Delivoria-Papadopoulos M, Bracci R, Pallini $V$ (2004). Proteomic approach to the identification of voltagedependent anion channel protein isoforms in guinea pig brain synaptosomes. Proteomics 4(5): 1335-1340. doi: 10.1002/pmic. 200300734

51. Palmieri F, Pierri CL (2010). Mitochondrial metabolite transport. Essays Biochem 47:37-52. doi: 10.1042/bse0470037

52. Shoshan-Barmatz V, Ben-Hail D (2012). VDAC, a multi-functional mitochondrial protein as a pharmacological target. Mitochondrion 12(1): 24-34. doi: 10.1016/j.mito.201.1.04.001

53. Aram L, Geula S, Arbel N, Shoshan-Barmatz V (2010). VDAC1 cysteine residues: topology and function in channel activity and apoptosis. Biochem J 427(3): 445-454. doi: 10.1042/BJ20091690

54. Shoshan-Barmatz V, Ben-Hail D, Admoni L, Krelin Y, Tripathi SS (2015). The mitochondrial voltage-dependent anion channel 1 in tumor cells. Biochim Biophys Acta 1848(10 Pt B): 2547-2575. doi: 10.1016/j.bbamem.2014.10.040

55. Vander Heiden MG, Chandel NS, Li XX, Schumacker PT, Colombini $M$, Thompson CB (2000). Outer mitochondrial membrane permeability can regulate coupled respiration and cell survival. Proc Natl Acad Sci U S A 97(9): 4666-4671. doi: 10.1073/pnas.090082297

56. Dolder M, Wendt S, Wallimann T (2001). Mitochondrial creatine kinase in contact sites: interaction with porin and adenine nucleotide translocase, role in permeability transition and sensitivity to oxidative damage. Biol Signals Recept 10(1-2): 93-111. doi: 46878
57. Gurnev PA, Rostovtseva TK, Bezrukov SM (2011). Tubulin-blocked state of VDAC studied by polymer and ATP partitioning. FEBS Lett 585(14): 2363-2366. doi: 10.1016/j.febslet.2011.06.008

58. Abu-Hamad S, Sivan S, Shoshan-Barmatz V (2006). The expression level of the voltage-dependent anion channel controls life and death of the cell. Proc Natl Acad Sci U S A 103(15): 5787-5792. doi: 10.1073/pnas.0600103103

59. Arif T, Vasilkovsky L, Refaely $Y$, Konson A, Shoshan-Barmatz V (2014). Silencing VDAC1 Expression by siRNA Inhibits Cancer Cell Proliferation and Tumor Growth In Vivo. Mol Ther Nucleic Acids 3:e159. doi: 10.1038/mtna.2014.9

60. Rone MB, Fan J, Papadopoulos V (2009). Cholesterol transport in steroid biosynthesis: role of protein-protein interactions and implications in disease states. Biochim Biophys Acta 1791(7): 646-658. doi: 10.1016/j.bbalip.2009.03.001

61. Aghazadeh $\mathrm{Y}$, Rone MB, Blonder J, Ye X, Veenstra TD, Hales DB, Culty M, Papadopoulos V (2012). Hormone-induced 14-3-3gamma adaptor protein regulates steroidogenic acute regulatory protein activity and steroid biosynthesis in MA-10 Leydig cells. J Biol Chem 287(19): 15380-15394. doi: 10.1074/jbc.M112.339580

62. Yu W, Gong JS, Ko M, Garver WS, Yanagisawa K, Michikawa M (2005). Altered cholesterol metabolism in Niemann-Pick type $C 1$ mouse brains affects mitochondrial function. J Biol Chem 280(12): 11731-11739. doi: 10.1074/jbc.M412898200

63. Pastorino JG, Hoek JB (2008). Regulation of hexokinase binding to VDAC. J Bioenerg Biomembr 40(3): 171-182. doi: 10.1007/s10863008-9148-8

64. Campbell AM, Chan SH (2008). Mitochondrial membrane cholesterol, the voltage dependent anion channel (VDAC), and the Warburg effect. J Bioenerg Biomembr 40(3): 193-197. doi: 10.1007/s10863008-9138-x

65. Lee K, Kerner J, Hoppel CL (2011). Mitochondrial carnitine palmitoyltransferase 1a (CPT1a) is part of an outer membrane fatty acid transfer complex. J Biol Chem 286(29): 25655-62. doi: 10.1074/jbc.M111.228692

66. Martel C, Allouche M, Esposti DD, Fanelli E, Boursier C, Henry C, Chopineau J, Calamita G, Kroemer G, Lemoine A, Brenner C (2013). Glycogen synthase kinase 3-mediated voltage-dependent anion channel phosphorylation controls outer mitochondrial membrane permeability during lipid accumulation. Hepatology 57(1): 93-102. doi: 10.1002/hep.25967

67. Qiu J, Tan Y-W, Hagenston AM, Martel M-A, Kneisel N, Skehel PA, Wyllie DJA, Bading H, Hardingham GE (2013). Mitochondrial calcium uniporter Mcu controls excitotoxicity and is transcriptionally repressed by neuroprotective nuclear calcium signals. Nat Commun 4: 2034. doi: $10.1038 /$ ncomms3034

68. Wenger JB, Chun SY, Dang DT, Luesch H, Dang LH (2011). Combination therapy targeting cancer metabolism. Med Hypotheses 76(2): 169-172. doi: 10.1016/j.mehy.2010.09.008

69. Cairns RA, Harris IS, Mak TW (2011). Regulation of cancer cell metabolism. Nat Rev Cancer 11(2): 85-95. doi: 10.1038/nrc2981

70. Maldonado EN, Patnaik J, Mullins MR, Lemasters JJ (2010). Free tubulin modulates mitochondrial membrane potential in cancer cells. 
Cancer Res 70(24): 10192-10201. doi: 10.1158/0008-5472.CAN-102429

71. Mathupala SP, Ko YH, Pedersen PL (2010). The pivotal roles of mitochondria in cancer: Warburg and beyond and encouraging prospects for effective therapies. Biochim Biophys Acta 1797(6-7): 12251230. doi: 10.1016/j.bbabio.2010.03.025

72. Nakashima RA, Paggi MG, Pedersen PL (1984). Contributions of glycolysis and oxidative phosphorylation to adenosine 5 '-triphosphate production in AS-30D hepatoma cells. Cancer Res 44(12 Pt 1): 57025706. PMID: 6498833

73. Singleterry J, Sreedhar A, Zhao $Y$ (2014). Components of cancer metabolism and therapeutic interventions. Mitochondrion 17:50-5. doi: 10.1016/j.mito.2014.05.010

74. Seyfried TN, Shelton LM (2010). Cancer as a metabolic disease. Nutr Metab (Lond) 7:7. doi: 10.1186/1743-7075-7-7

75. Seyfried TN (2015). Cancer as a mitochondrial metabolic disease. Front Cell Dev Biol 3:43. doi: 10.3389/fcell.2015.00043

76. Loeb LA (2001). A mutator phenotype in cancer. Cancer Res 61(8): 3230-3239. PMID: 11309271

77. Gatenby RA, Gillies RJ (2004). Why do cancers have high aerobic glycolysis? Nat Rev Cancer 4(11): 891-899. doi: 10.1038/nrc1478

78. Hanahan D, Weinberg RA (2011). Hallmarks of cancer: the next generation. Cell 144(5): 646-674. doi: 10.1016/j.cell.2011.02.013

79. Koppenol WH, Bounds PL, Dang CV (2011). Otto Warburg's contributions to current concepts of cancer metabolism. Nat Rev Cancer 11(5): 325-337. doi: 10.1038/nrc3038

80. Majeed R. HA, Qurishi Y., Qazi A.K., Hussain A., Ahmed M., Najar R.A., Bhat J.A., Singh S.K. and Saxena A.K. (2012). Therapeutic Targeting of Cancer Cell Metabolism: Role of Metabolic Enzymes, Oncogenes and Tumor Suppressor Genes. J Cancer Sci Ther 4(9): 281-291. doi: 10.4172/1948-5956.1000156

81. Mathupala SP, Ko YH, Pedersen PL (2006). Hexokinase II: cancer's double-edged sword acting as both facilitator and gatekeeper of malignancy when bound to mitochondria. Oncogene 25(34): 4777-4786. doi: $10.1038 /$ sj.onc. 1209603

82. Pedersen PL, Mathupala S, Rempel A, Geschwind JF, Ko YH (2002). Mitochondrial bound type II hexokinase: a key player in the growth and survival of many cancers and an ideal prospect for therapeutic intervention. Biochim Biophys Acta 1555(1-3): 14-20. doi: 10.1016/s0005-2728(02)00248-7

83. Majewski N, Nogueira V, Robey RB, Hay N (2004). Akt inhibits apoptosis downstream of BID cleavage via a glucose-dependent mechanism involving mitochondrial hexokinases. Mol Cell Biol 24(2): 730-740. doi: 10.1128/MCB.24.2.730-740.2004

84. Pastorino JG, Hoek JB, Shulga N (2005). Activation of glycogen synthase kinase 3beta disrupts the binding of hexokinase II to mitochondria by phosphorylating voltage-dependent anion channel and potentiates chemotherapy-induced cytotoxicity. Cancer Res 65(22): 10545-10554. doi: 10.1158/0008-5472.CAN-05-1925

85. Maldonado EN, Sheldon KL, DeHart DN, Patnaik J, Manevich Y, Townsend DM, Bezrukov SM, Rostovtseva TK, Lemasters JJ (2013). Voltage-dependent anion channels modulate mitochondrial metabo- lism in cancer cells: regulation by free tubulin and erastin. J Biol Chem 288(17): 11920-11929. doi: 10.1074/jbc.M112..433847

86. Rostovtseva TK, Sheldon KL, Hassanzadeh E, Monge C, Saks V, Bezrukov SM, Sackett DL (2008). Tubulin binding blocks mitochondrial voltage-dependent anion channel and regulates respiration. Proc Natl Acad Sci U S A 105(48): 18746-18751. doi: 10.1073/pnas.0806303105

87. Timohhina N, Guzun R, Tepp K, Monge C, Varikmaa M, Vija H, Sikk $P$, Kaambre T, Sackett D, Saks V (2009). Direct measurement of energy fluxes from mitochondria into cytoplasm in permeabilized cardiac cells in situ: some evidence for Mitochondrial Interactosome. J Bioenerg Biomembr 41(3): 259-275. doi: 10.1007/s10863-009-9224-8

88. Maldonado EN (2017). VDAC-Tubulin, an Anti-Warburg ProOxidant Switch. Front Oncol 7:4. doi: 10.3389/fonc.2017.00004

89. Colombini M (2004). VDAC: the channel at the interface between mitochondria and the cytosol. Mol Cell Biochem 256-257(1-2): 107115. doi: 10.1023/B:MCBI.0000009862.17396.8d

90. Koren I, Raviv Z, Shoshan-Barmatz V (2010). Downregulation of voltage-dependent anion channel-1 expression by RNA interference prevents cancer cell growth in vivo. Cancer Biol Ther 9(12): 10461052. doi: $10.4161 /$ cbt.9.12.11879

91. Arif T, Kerlin Y, Nakdimon I, Benharroch D, Paul A, Dadon-Klein D, Shoshan-Barmatz V (2017). VDAC1 is a molecular target in glioblastoma, with its depletion leading to reprogrammed metabolism and reversed oncogenic properties. Neuro Oncol. doi: 10.1093/neuonc/now297

92. Bargaje R, Gupta S, Sarkeshik A, Park R, Xu T, Sarkar M, Halimani $M$, Roy SS, Yates J, Pillai B (2012). Identification of novel targets for miR-29a using miRNA proteomics. PLoS ONE 7(8): e43243. doi: 10.1371/journal.pone.0043243

93. Li QQ, Zhang L, Wan HY, Liu M, Li X, Tang H (2015). CREB1-driven expression of miR-320a promotes mitophagy by down-regulating VDAC1 expression during serum starvation in cervical cancer cells. Oncotarget 6(33): 34924-34940. doi: 10.18632/oncotarget.5318

94. Wang F, Qiang Y, Zhu L, Jiang Y, Wang Y, Shao X, Yin L, Chen J, Chen $Z$ (2016). MicroRNA-7 downregulates the oncogene VDAC1 to influence hepatocellular carcinoma proliferation and metastasis. Tumour Biol 37(8): 10235-10246. doi: 10.1007/s13277-016-4836-1

95. Chaudhuri AD, Choi DC, Kabaria S, Tran A, Junn E (2016). MicroRNA-7 Regulates the Function of Mitochondrial Permeability Transition Pore by Targeting VDAC1 Expression. J Biol Chem 291(12): 64836493. doi: 10.1074/jbc.M115.691352

96. Li X, Wang H, Yao B, Xu W, Chen J, Zhou X (2016). IncRNA H19/miR-675 axis regulates cardiomyocyte apoptosis by targeting VDAC1 in diabetic cardiomyopathy. Sci Rep 6:36340. doi: $10.1038 /$ srep36340

97. Manczak M, Reddy PH (2012). Abnormal interaction of VDAC1 with amyloid beta and phosphorylated tau causes mitochondrial dysfunction in Alzheimer's disease. Human molecular genetics 21(23): 5131-5146. doi: 10.1093/hmg/dds360

98. Cuadrado-Tejedor M, Vilarino M, Cabodevilla F, Del Rio J, Frechilla D, Perez-Mediavilla A (2011). Enhanced expression of the voltagedependent anion channel 1 (VDAC1) in Alzheimer's disease transgenic mice: an insight into the pathogenic effects of amyloid-beta. Journal 
of Alzheimer's disease : JAD 23(2): 195-206. doi: 10.3233/JAD-2010100966.

99. Perez-Gracia E, Torrejon-Escribano B, Ferrer I (2008). Dystrophic neurites of senile plaques in Alzheimer's disease are deficient in cytochrome c oxidase. Acta Neuropathol 116(3): 261-268. doi: 10.1007/s00401-008-0370-6

100. Liao Z, Liu D, Tang L, Yin D, Yin S, Lai S, Yao J, He M (2015). Longterm oral resveratrol intake provides nutritional preconditioning against myocardial ischemia/reperfusion injury: involvement of VDAC1 downregulation. Mol Nutr Food Res 59(3): 454-464. doi: 10.1002/mnfr.201400730

101. Ahmed M, Muhammed SJ, Kessler B, Salehi A (2010). Mitochondrial proteome analysis reveals altered expression of voltage dependent anion channels in pancreatic beta-cells exposed to high glucose. Islets 2(5): 283-292. doi: 10.4161/isl.2.5.12639

102. Gong D, Chen X, Middleditch M, Huang L, Vazhoor Amarsingh G, Reddy S, Lu J, Zhang S, Ruggiero K, Phillips AR, Cooper GJ (2009). Quantitative proteomic profiling identifies new renal targets of copper(II)-selective chelation in the reversal of diabetic nephropathy in rats. Proteomics 9(18): 4309-4320. doi: 10.1002/pmic.200900285

103. Kroemer G, Galluzzi L, Brenner C (2007). Mitochondrial membrane permeabilization in cell death. Physiol Rev 87(1): 99-163. doi: 10.1152/physrev.00013.2006

104. Shoshan-Barmatz V, Arbel N, Arzoine I (2008). VDAC, the voltagedependent anion channel: function, regulation \& mitochondrial signaling in cell life and death. Cell Science 4:74-118.

105. Lemasters JJ, Holmuhamedov E (2006). Voltage-dependent anion channel (VDAC) as mitochondrial governator--thinking outside the box. Biochim Biophys Acta 1762(2): 181-190. doi: 10.1016/j.bbadis.2005.10.006

106. Vander Heiden MG, Li XX, Gottleib E, Hill RB, Thompson CB, Colombini $M$ (2001). Bcl-xL promotes the open configuration of the voltage-dependent anion channel and metabolite passage through the outer mitochondrial membrane. J Biol Chem 276(22): 19414-19419. doi: 10.1074/jbc.M101590200

107. Biasutto L, Azzolini M, Szabò I, Zoratti M (2016). The mitochondrial permeability transition pore in AD 2016: An update. Biochimica et Biophysica Acta 1863(10): 2515-2530. doi: 10.1016/j.bbamcr.2016.02.012

108. Antignani A, Youle RJ (2006). How do Bax and Bak lead to permeabilization of the outer mitochondrial membrane? Curr Opin Cell Biol 18(6): 685-689. doi: 10.1016/j.ceb.2006.10.004

109. Lovell JF, Billen LP, Bindner S, Shamas-Din A, Fradin C, Leber B, Andrews DW (2008). Membrane binding by tBid initiates an ordered series of events culminating in membrane permeabilization by Bax. Cell 135(6): 1074-1084. doi: 10.1016/j.cell.2008.11.010

110. Banerjee J, Ghosh S (2004). Bax increases the pore size of rat brain mitochondrial voltage-dependent anion channel in the presence of tBid. Biochem Biophys Res Commun 323(1): 310-314. doi: 10.1016/j.bbrc.2004.08.094

111. Shimizu S, Tsujimoto Y (2000). Proapoptotic BH3-only Bcl-2 family members induce cytochrome $c$ release, but not mitochondrial membrane potential loss, and do not directly modulate voltage-dependent anion channel activity. Proc Natl Acad Sci U S A 97(2): 577-582. doi: 10.1073/pnas.97.2.577

112. Keinan N, Pahima H, Ben-Hail D, Shoshan-Barmatz V (2013). The role of calcium in VDAC1 oligomerization and mitochondria-mediated apoptosis. Biochim Biophys Acta 1833(7): 1745-1754. doi: 10.1016/j.bbamcr.2013.03.017

113. Weisthal S, Keinan N, Ben-Hail D, Arif T, Shoshan-Barmatz V (2014). $\mathrm{Ca}(2+)$-mediated regulation of VDAC1 expression levels is associated with cell death induction. Biochim Biophys Acta 1843(10) 2270-2281. doi: 10.1016/j.bbamcr.2014.03.021

114. Martinou JC, Desagher S, Antonsson B (2000). Cytochrome c release from mitochondria: all or nothing. Nat Cell Biol 2(3): E41-43. doi: $10.1038 / 35004069$

115. Halestrap AP, McStay GP, Clarke SJ (2002). The permeability transition pore complex: another view. Biochimie 84(2-3): 153-166 doi: 10.1016/s0300-9084(02)01375-5

116. Doran E, Halestrap AP (2000). Cytochrome c release from isolated rat liver mitochondria can occur independently of outer-membrane rupture: possible role of contact sites. Biochem J 348 (Pt 2):343-350. doi: 10.1042/0264-6021:3480343

117. Tsujimoto $Y$, Shimizu S (2002). The voltage-dependent anion channel: an essential player in apoptosis. Biochimie 84(2-3): 187-193. doi: 10.1016/s0300-9084(02)01370-6

118. Abu-Hamad S, Zaid H, Israelson A, Nahon E, Shoshan-Barmatz V (2008). Hexokinase-I protection against apoptotic cell death is mediated via interaction with the voltage-dependent anion channel-1: mapping the site of binding. J Biol Chem 283(19): 13482-13490. doi: 10.1074/jbc.M708216200

119. Ghosh T, Pandey N, Maitra A, Brahmachari SK, Pillai B (2007). A role for voltage-dependent anion channel Vdac1 in polyglutaminemediated neuronal cell death. PLoS One 2(11): e1170. doi: 10.1371/journal.pone.0001170

120. Godbole A, Varghese J, Sarin A, Mathew MK (2003). VDAC is a conserved element of death pathways in plant and animal systems. Biochim Biophys Acta 1642(1-2): 87-96. doi: 10.1016/s01674889(03)00102-2

121. Lu AJ, Dong CW, Du CS, Zhang QY (2007). Characterization and expression analysis of Paralichthys olivaceus voltage-dependent anion channel (VDAC) gene in response to virus infection. Fish Shellfish Immunol 23(3): 601-613. doi: 10.1016/j.fsi.2007.01.007

122. Zaid H, Abu-Hamad S, Israelson A, Nathan I, Shoshan-Barmatz V (2005). The voltage-dependent anion channel-1 modulates apoptotic cell death. Cell Death Differ 12(7): 751-760. doi: 10.1038/sj.cdd.4401599

123. Israelson A, Zaid H, Abu-Hamad S, Nahon E, Shoshan-Barmatz V (2008). Mapping the ruthenium red-binding site of the voltagedependent anion channel-1. Cell Calcium 43(2): 196-204. doi: 10.1016/j.ceca.2007.05.006

124. Azoulay-Zohar H, Israelson A, Abu-Hamad S, Shoshan-Barmatz V (2004). In self-defence: hexokinase promotes voltage-dependent anion channel closure and prevents mitochondria-mediated apoptotic cell death. Biochem J 377(Pt 2): 347-355. doi: 10.1042/BJ20031465 
125. Tajeddine N, Galluzzi L, Kepp O, Hangen E, Morselli E, Senovilla L, Araujo N, Pinna G, Larochette N, Zamzami N, Modjtahedi N, HarelBellan A, Kroemer G (2008). Hierarchical involvement of Bak, VDAC1 and Bax in cisplatin-induced cell death. Oncogene 27(30): 4221-4232. doi: $10.1038 / o n c .2008 .63$

126. Tomasello F, Messina A, Lartigue L, Schembri L, Medina C, Reina S, Thoraval D, Crouzet M, Ichas F, De Pinto V, De Giorgi F (2009). Outer membrane VDAC1 controls permeability transition of the inner mitochondrial membrane in cellulo during stress-induced apoptosis. Cell Res 19(12): 1363-1376. doi: 10.1038/cr.2009.98

127. Yuan S, Fu $Y$, Wang $X$, Shi $H$, Huang $Y$, Song $X$, Li L, Song $N$, Luo $Y$ (2008). Voltage-dependent anion channel 1 is involved in endostatininduced endothelial cell apoptosis. FASEB J 22(8): 2809-2820. doi: 10.1096/fj.08-107417

128. Shimizu S, Narita M, Tsujimoto $Y$ (1999). Bcl-2 family proteins regulate the release of apoptogenic cytochrome $c$ by the mitochondrial channel VDAC. Nature 399(6735): 483-487. doi: 10.1038/20959

129. Madesh M, Hajnoczky G (2001). VDAC-dependent permeabilization of the outer mitochondrial membrane by superoxide induces rapid and massive cytochrome c release. J Cell Biol 155(6): 1003-1015. doi: $10.1083 /$ jcb.200105057

130. Betaneli V, Petrov EP, Schwille P (2012). The role of lipids in VDAC oligomerization. Biophys J 102(3): 523-531. doi: 10.1016/j.bpj.2011.12.049

131. Vaseva AV, Marchenko ND, Ji K, Tsirka SE, Holzmann S, Moll UM (2012). p53 opens the mitochondrial permeability transition pore to trigger necrosis. Cell 149(7): 1536-48. doi: 10.1016/j.cell.2012.05.014

132. Ben-Hail D, Shoshan-Barmatz V (2016). VDAC1-interacting anion transport inhibitors inhibit VDAC1 oligomerization and apoptosis. Biochim Biophys Acta $1863(7$ Pt A): 1612-1623. doi: 10.1016/j.bbamcr.2016.04.002

133. Chen H, Gao W, Yang Y, Guo S, Wang H, Wang W, Zhang S, Zhou Q, Xu H, Yao J, Tian Z, Li B, Cao W, Zhang Z, Tian Y (2014). Inhibition of VDAC1 prevents $\mathrm{Ca}(2)(+)$-mediated oxidative stress and apoptosis induced by 5 -aminolevulinic acid mediated sonodynamic therapy in THP-1 macrophages. Apoptosis 19(12): 1712-1726. doi: 10.1007/s10495-014-1045-5

134. Ben-Hail D, Begas-Shvartz, R., Shalev, M., Gruzman, A. and Shoshan-Barmatz. V. (2016). The mitochondrial protein VDAC1 as a target for novel anti-apoptotic compounds. Cell Death and Dis 16(9):820828. doi: 10.1074/jbc.M116.744284

135. Obulesu M, Lakshmi MJ (2014). Apoptosis in Alzheimer's disease: an understanding of the physiology, pathology and therapeutic avenues. Neurochemical research 39(12): 2301-2312. doi: 10.1007/s11064-014-1454-4

136. Sureda FX, Junyent F, Verdaguer E, Auladell C, Pelegri C, Vilaplana J, Folch J, Canudas AM, Zarate CB, Palles M, Camins A (2011). Antiapoptotic drugs: a therapautic strategy for the prevention of neurodegenerative diseases. Curr Pharm Des 17(3): 230-245. doi: $10.2174 / 138161211795049732$

137. Kostin S, Pool L, Elsasser A, Hein S, Drexler HC, Arnon E, Hayakawa Y, Zimmermann R, Bauer E, Klovekorn WP, Schaper J (2003). Myocytes die by multiple mechanisms in failing human hearts. Circ Res 92(7): 715-724. doi: 10.1161/01.RES.0000067471.95890.5C
138. Kroemer G, El-Deiry WS, Golstein P, Peter ME, Vaux D, Vandenabeele $\mathrm{P}$, Zhivotovsky B, Blagosklonny MV, Malorni W, Knight RA, Piacentini M, Nagata S, Melino G (2005). Classification of cell death: recommendations of the Nomenclature Committee on Cell Death. Cell Death Differ 12 (Suppl 2):1463-1467. doi: 10.1038/sj.cdd.4401724

139. Marunouchi T, Tanonaka K (2015). Cell Death in the Cardiac Myocyte. Biol Pharm Bull 38(8): 1094-1097. doi: 10.1248/bpb.b15-00288

140. Nawarak J, Huang-Liu R, Kao SH, Liao HH, Sinchaikul S, Chen ST, Cheng SL (2009). Proteomics analysis of A375 human malignant melanoma cells in response to arbutin treatment. Biochim Biophys Acta 1794(2): 159-167. doi: 10.1016/j.bbapap.2008.09.023

141. Jiang N, Kham SK, Koh GS, Suang Lim JY, Ariffin H, Chew FT, Yeoh $A E$ (2011). Identification of prognostic protein biomarkers in childhood acute lymphoblastic leukemia (ALL). J Proteomics 74(6): 843857. doi: 10.1016/j.jprot.2011.02.034

142. Liu Z, Bengtsson S, Krogh $M$, Marquez $M$, Nilsson $S$, James $P$, Aliaya A, Holmberg AR (2007). Somatostatin effects on the proteome of the LNCaP cell-line. Int J Oncol 30(5): 1173-1179. doi: 10.3892/ijo.30.5.1173

143. Moin SM, Panteva M, Jameel S (2007). The hepatitis E virus Orf3 protein protects cells from mitochondrial depolarization and death. J Biol Chem 282(29): 21124-21133. doi: 10.1074/jbc.M701696200

144. Jung JY, Han CR, Jeong YJ, Kim HJ, Lim HS, Lee KH, Park HO, Oh WM, Kim SH, Kim WJ (2007). Epigallocatechin gallate inhibits nitric oxide-induced apoptosis in rat PC12 cells. Neurosci Lett 411(3): 222-7. doi: 10.1016/j.neulet.2006.09.089

145. Voehringer DW, Hirschberg DL, Xiao J, Lu Q, Roederer M, Lock CB, Herzenberg LA, Steinman L (2000). Gene microarray identification of redox and mitochondrial elements that control resistance or sensitivity to apoptosis. Proc Natl Acad Sci U S A 97(6): 2680-2685. doi 10.1073/pnas.97.6.2680

146. Chen Y, Craigen WJ, Riley DJ (2009). Nek1 regulates cell death and mitochondrial membrane permeability through phosphorylation of VDAC1. Cell Cycle 8(2): 257-67. doi: 10.4161/cc.8.2.7551

147. Castagna A, Antonioli $P$, Astner $H$, Hamdan M, Righetti SC, Perego P, Zunino F, Righetti PG (2004). A proteomic approach to cisplatin resistance in the cervix squamous cell carcinoma cell line A431. Proteomics 4(10): 3246-3267. doi: 10.1002/pmic.200400835

148. Leone A, Roca MS, Ciardiello C, Terranova-Barberio M, Vitagliano C, Ciliberto G, Mancini R, Di Gennaro E, Bruzzese F, Budillon A (2015) Vorinostat synergizes with EGFR inhibitors in NSCLC cells by increasing ROS via up-regulation of the major mitochondrial porin VDAC1 and modulation of the c-Myc-NRF2-KEAP1 pathway. Free Radic Biol Med 89:287-299. doi: 10.1016/j.freeradbiomed.2015.07.155

149. Anis $Y$ (2006). Involvement of $\mathrm{Ca} 2+$ in the apoptotic process friends or foes. Pathways 2: 2-7.

150. Berridge MJ BM, Roderick HL. (2003). Calcium signalling: Dynamics, homeostasis and remodelling. Nature Review Molecular Cell Biology 4:517-529. doi: 10.1038/nrm1155

151. Rizzuto R, De Stefani D, Raffaello A, Mammucari C (2012). Mitochondria as sensors and regulators of calcium signalling. Nat Rev Mol Cell Biol 13(9): 566-578. doi: 10.1038/nrm3412 
152. Baughman JM, Perocchi F, Girgis HS, Plovanich M, Belcher-Timme CA, Sancak Y, Bao XR, Strittmatter L, Goldberger O, Bogorad RL, Koteliansky V, Mootha VK (2011). Integrative genomics identifies MCU as an essential component of the mitochondrial calcium uniporter. $\mathrm{Na}$ ture: 476(7360): 341-5. doi: 10.1038/nature10234

153. De Stefani D, Raffaello A, Teardo E, Szabo I, Rizzuto R (2011). A forty-kilodalton protein of the inner membrane is the mitochondrial calcium uniporter. Nature 476(7360): 336-340. doi: $10.1038 /$ nature10230

154. Palty R, Silverman WF, Hershfinkel M, Caporale T, Sensi SL, Parnis J, Nolte C, Fishman D, Shoshan-Barmatz V, Herrmann S, Khananshvili $D$, Sekler I (2010). NCLX is an essential component of mitochondrial $\mathrm{Na}+\mathrm{Ca} 2+$ exchange. Proc Natl Acad Sci U S A 107(1): 436-441. doi: 10.1073/pnas.0908099107

155. Shoshan-Barmatz V, De S, Meir A (2017). The Mitochondrial Voltage-Dependent Anion Channel 1, Ca2+ Transport, Apoptosis, and Their Regulation. Front Oncol 7:60. doi: 10.3389/fonc.2017.00060

156. Bathori G, Csordas G, Garcia-Perez C, Davies E, Hajnoczky G (2006). Ca2+-dependent control of the permeability properties of the mitochondrial outer membrane and voltage-dependent anionselective channel (VDAC) .J Biol Chem 281(25): 17347-17358. doi: 10.1074/jbc.M600906200

157. Gincel D, Zaid H, Shoshan-Barmatz V (2001). Calcium binding and translocation by the voltage-dependent anion channel: a possible regulatory mechanism in mitochondrial function. Biochem J 358(Pt 1): 147-155. doi: 10.1042/0264-6021:3580147

158. Rapizzi E, Pinton P, Szabadkai G, Wieckowski MR, Vandecasteele G, Baird G, Tuft RA, Fogarty KE, Rizzuto R (2002). Recombinant expression of the voltage-dependent anion channel enhances the transfer of Ca2+ microdomains to mitochondria. J Cell Biol 159(4): 613-624. doi: 10.1083/jcb.200205091

159. Tan W, Colombini M (2007). VDAC closure increases calcium ion flux. Biochim Biophys Acta 1768(10): 2510-5. doi: 10.1016/j.bbamem.2007.06.002

160. Israelson A, Abu-Hamad S, Zaid H, Nahon E, Shoshan-Barmatz V (2007). Localization of the voltage-dependent anion channel-1 Ca2+binding sites. Cell Calcium 41(3): 235-244. doi: 10.1016/j.ceca.2006.06.005

161. Gincel D, Vardi N, Shoshan-Barmatz V (2002). Retinal voltagedependent anion channel: characterization and cellular localization. Invest Ophthalmol Vis Sci 43(7): 2097-2104. PMID: 12091402

162. Israelson A, Arzoine L, Abu-hamad S, Khodorkovsky V, ShoshanBarmatz $V$ (2005). A photoactivable probe for calcium binding proteins. Chem Biol 12(11): 1169-1178. doi: 10.1016/j.chembiol.2005.08.006

163. Csordás G, Renken C, Várnai $P$, Walter L, Weaver $D$, Buttle KF, Balla T, Mannella CA, Hajnóczky G (2006). Structural and functional features and significance of the physical linkage between ER and mitochondria. The Journal of Cell Biology 174(7): 915-921. doi: 10.1083/jcb.200604016

164. de Brito OM, Scorrano L (2008). Mitofusin 2 tethers endoplasmic reticulum to mitochondria. Nature 456(7222): 605-61. doi: $10.1038 /$ nature07534
165. de Brito OM, Scorrano L (2009). Mitofusin-2 regulates mitochondrial and endoplasmic reticulum morphology and tethering: the role of Ras. Mitochondrion 9(3): 222-226. doi: 10.1016/j.mito.2009.02.005

166. Buttke TM, Sandstrom PA (1994). Oxidative stress as a mediator of apoptosis. Immunology today 15(1): 7-10. doi: 10.1016/01675699(94)90018-3

167. Fiskum G (2000). Mitochondrial participation in ischemic and traumatic neural cell death. Journal of neurotrauma 17(10): 843-55 doi: 10.1089/neu.2000.17.843

168. Patel M, Day BJ, Crapo JD, Fridovich I, McNamara JO (1996). Requirement for superoxide in excitotoxic cell death. Neuron 16(2): 345-355. doi: 10.1016/S0896-6273(00)80052-5

169. Yuan J, Yankner BA (2000). Apoptosis in the nervous system. Nature 407(6805): 802-809. doi: 10.1038/35037739

170. Auten RL, Davis JM (2009). Oxygen toxicity and reactive oxygen species: the devil is in the details. Pediatr Res 66(2): 121-127. doi: 10.1203/PDR.0b013e3181a9eafb

171. Chen Q, Vazquez EJ, Moghaddas S, Hoppel CL, Lesnefsky EJ (2003). Production of reactive oxygen species by mitochondria: central role of complex III. J Biol Chem 278(38): 36027-36031. doi: 10.1074/jbc.M304854200

172. Quinlan CL, Orr AL, Perevoshchikova IV, Treberg JR, Ackrell BA, Brand MD (2012). Mitochondrial complex II can generate reactive oxygen species at high rates in both the forward and reverse reactions. J Biol Chem 287(32): 27255-27264. doi: 10.1074/jbc.M112.374629

173. Tribble DL, Jones DP, Edmondson DE (1988). Effect of hypoxia on tert-butylhydroperoxide-induced oxidative injury in hepatocytes. Mol Pharmacol 34(3): 413-420. PMID: 3419429

174. Fridovich I (1997). Superoxide anion radical (O2-.), superoxide dismutases, and related matters. J Biol Chem 272(30): 18515-18517. doi: $10.1074 / j b c .272 .30 .18515$

175. Veal EA, Day AM, Morgan BA (2007). Hydrogen peroxide sensing and signaling. Mol Cell 26(1): 1-14. doi: 10.1016/j.molcel.2007.03.016

176. Clerkin JS, Naughton R, Quiney C, Cotter TG (2008). Mechanisms of ROS modulated cell survival during carcinogenesis. Cancer Lett 266(1): 30-36. doi: 10.1016/j.canlet.2008.02.029

177. Giles GI (2006). The redox regulation of thiol dependent signaling pathways in cancer. Curr Pharm Des 12(34): 4427-4443. doi: $10.2174 / 138161206779010549$

178. Ushio-Fukai M, Nakamura Y (2008). Reactive oxygen species and angiogenesis: NADPH oxidase as target for cancer therapy. Cancer Lett 266(1): 37-52. doi: 10.1016/j.canlet.2008.02.044

179. Schenkel LC, Bakovic M (2014). Formation and regulation of mitochondrial membranes. Int J Cell Biol 2014:709828. doi: $10.1155 / 2014 / 709828$

180. Zhang Y, Marcillat O, Giulivi C, Ernster L, Davies KJ (1990). The oxidative inactivation of mitochondrial electron transport chain components and ATPase. J Biol Chem 265(27): 16330-16336. PMID: 2168888

181. Kamata H, Honda S, Maeda S, Chang L, Hirata H, Karin M (2005). Reactive oxygen species promote TNFalpha-induced death and sus- 
tained JNK activation by inhibiting MAP kinase phosphatases. Cell 120(5): 649-661. doi: 10.1016/j.cell.2004.12.041

182. Son Y, Cheong YK, Kim NH, Chung HT, Kang DG, Pae HO (2011). Mitogen-Activated Protein Kinases and Reactive Oxygen Species: How Can ROS Activate MAPK Pathways? J Signal Transduct 2011:792639. doi: 10.1155/2011/792639

183. Beckman KB, Ames BN (1997). Oxidative decay of DNA. J Biol Chem 272(32): 19633-19636. PMID: 9289489

184. Handy DE, Loscalzo J (2012). Redox regulation of mitochondrial function. Antioxidants \& redox signaling 16(11).1367-1323 :doi: 10.1089/ars.2011.4123

185. Mailloux RJ, McBride SL, Harper ME (2013). Unearthing the secrets of mitochondrial ROS and glutathione in bioenergetics. Trends Biochem Sci 38(12): 592-602. doi: 10.1016/j.tibs.2013.09.001

186. Sena LA, Chandel NS (2012). Physiological roles of mitochondrial reactive oxygen species. Mol Cell 48(2): 158-167. doi: 10.1016/j.molcel.2012.09.025

187. Trachootham D, Lu W, Ogasawara MA, Nilsa RD, Huang P (2008). Redox regulation of cell survival. Antioxidants \& redox signaling 10(8): 1343-1374. doi: 10.1089/ars.2007.1957

188. Barber SC, Mead RJ, Shaw PJ (2006). Oxidative stress in ALS: a mechanism of neurodegeneration and a therapeutic target. Biochim Biophys Acta 1762(11-12): 1051-1067. doi: 10.1016/j.bbadis.2006.03.008

189. Ott M, Gogvadze V, Orrenius S, Zhivotovsky B (2007). Mitochondria, oxidative stress and cell death. Apoptosis 12(5): 913-922. doi: 10.1007/s10495-007-0756-2

190. Ahmad A, Ahmad S, Schneider BK, Allen CB, Chang LY, White CW (2002). Elevated expression of hexokinase II protects human lung epithelial-like A549 cells against oxidative injury. Am J Physiol Lung Cell Mol Physiol 283(3): L573-584. doi: 10.1152/ajplung.00410.2001

191. da-Silva WS, Gomez-Puyou A, de Gomez-Puyou MT, MorenoSanchez R, De Felice FG, de Meis L, Oliveira MF, Galina A (2004). Mitochondrial bound hexokinase activity as a preventive antioxidant defense: steady-state ADP formation as a regulatory mechanism of membrane potential and reactive oxygen species generation in mitochondria. J Biol Chem 279(38): 39846-39855. doi: 10.1074/jbc.M403835200

192. Sun L, Shukair S, Naik TJ, Moazed F, Ardehali H (2008). Glucose phosphorylation and mitochondrial binding are required for the protective effects of hexokinases I and II. Mol Cell Biol 28(3): 1007-1017. doi: 10.1128/MCB.00224-07.

193. Bryson JM, Coy PE, Gottlob K, Hay N, Robey RB (2002). Increased hexokinase activity, of either ectopic or endogenous origin, protects renal epithelial cells against acute oxidant-induced cell death. J Biol Chem 277(13): 11392-11400. doi: 10.1074/jbc.M110927200

194. Tikunov A, Johnson CB, Pediaditakis $P$, Markevich N, Macdonald JM, Lemasters JJ, Holmuhamedov E (2010). Closure of VDAC causes oxidative stress and accelerates the $\mathrm{Ca}(2+)$-induced mitochondrial permeability transition in rat liver mitochondria. Arch Biochem Biophys 495(2): 174-181. doi: 10.1016/j.abb.2010.01.008

195. Han D, Antunes F, Canali R, Rettori D, Cadenas E (2003). Voltagedependent anion channels control the release of the superoxide anion from mitochondria to cytosol. J Biol Chem 278(8): 5557-5563. doi: 10.1074/jbc.M210269200

196. Saeed U, Durgadoss L, Valli RK, Joshi DC, Joshi PG, Ravindranath V (2008). Knockdown of cytosolic glutaredoxin 1 leads to loss of mitochondrial membrane potential: implication in neurodegenerative diseases. PLoS One 3(6): e2459. doi: 10.1371/journal. pone.0002459

197. Reina S,Checchetto V, Saletti R, Gupta A, Chaturvedi D, Guardiani C, Guarino F, Scorciapino MA, Magri A, Foti S, Ceccarelli M, Messina AA, Mahalakshmi R, Szabo I, De Pinto V (2016). VDAC3 as a sensor of oxidative state of the intermembrane space of mitochondria :the putative role of cysteine residue modifications. Oncotarget 7(3): 22492268. doi: 10.18632/oncotarget. 6850

198. Ding W, Hudson LG, Liu KJ (2005). Inorganic arsenic compounds cause oxidative damage to DNA and protein by inducing ROS and RNS generation in human keratinocytes. Mol Cell Biochem 279(1-2): 105112. doi: 10.1007/s11010-005-8227-y

199. Shi H, Hudson LG, Ding W, Wang S, Cooper KL, Liu S, Chen Y, Shi $X$, Liu KJ (2004). Arsenite causes DNA damage in keratinocytes via generation of hydroxyl radicals. Chem Res Toxicol 17(7): 871-878. doi 10.1021/tx049939e

200. Olson RD, Boerth RC, Gerber JG, Nies AS (1981). Mechanism of adriamycin cardiotoxicity: evidence for oxidative stress. Life Sci 29(14): 1393-1401. doi: 10.1016/0024-3205(81)90001-1

201. Simamura E, Hirai K, Shimada H, Koyama J, Niwa Y, Shimizu S (2006). Furanonaphthoquinones cause apoptosis of cancer cells by inducing the production of reactive oxygen species by the mitochondrial voltage-dependent anion channel. Cancer Biol Ther 5(11): 15231529. doi: 10.4161/cbt.5.11.3302

202. Le Bras M, Clement MV, Pervaiz S, Brenner C (2005). Reactive oxygen species and the mitochondrial signaling pathway of cell death. Histol Histopathol 20(1): 205-219. doi: 10.14670/HH-20.205

203. Li Q, Sato EF, Zhu X, Inoue M (2009). A simultaneous release of SOD1 with cytochrome $c$ regulates mitochondria-dependent apoptosis. Mol Cell Biochem 322(1-2): 151-159. doi: 10.1007/s11010-0089952-9

204. Brahimi-Horn MC, Lacas-Gervais S, Adaixo R, Ilc K, Rouleau M, Notte A, Dieu M, Michiels C, Voeltzel T, Maguer-Satta V, Pelletier J, Ilie M, Hofman P, Manoury B, Schmidt A, Hiller S, Pouyssegur J, Mazure NM (2015). Local mitochondrial-endolysosomal microfusion cleaves voltage-dependent anion channel 1 to promote survival in hypoxia. Mol Cell Biol 35(9): 1491-1505. doi: 10.1128/MCB.01402-14

205. Mazure NM (2016). News about VDAC1 in Hypoxia. Frontiers in Oncology 6: 193. doi: 10.3389/fonc.2016.00193

206. Brahimi-Horn MC, Ben-Hail D, Ilie M, Gounon P, Rouleau M, Hofman V, Doyen J, Mari B, Shoshan-Barmatz V, Hofman P, Pouyssegur J, Mazure NM (2012). Expression of a truncated active form of VDAC1 in lung cancer associates with hypoxic cell survival and correlates with progression to chemotherapy resistance. Cancer Res 72(8): 2140-2150. doi: 10.1158/0008-5472.CAN-11-3940

207. Ko JH, Gu W, Lim I, Zhou T, Bang H (2014). Expression profiling of mitochondrial voltage-dependent anion channel-1 associated genes predicts recurrence-free survival in human carcinomas. PLoS One 9(10): e110094. doi: 10.1371/journal.pone.0110094 
208. De Pinto V, Messina A, Lane DJ, Lawen A (2010). Voltagedependent anion-selective channel (VDAC) in the plasma membrane. FEBS Lett 584(9): 1793-1799. doi: 10.1016/j.febslet.2010.02.049

209. Manna B, Bhattacharya T, Kahali B, Ghosh TC (2009). Evolutionary constraints on hub and non-hub proteins in human protein interaction network: insight from protein connectivity and intrinsic disorder. Gene 434(1-2): 50-5. doi: 10.1016/j.gene.2008.12.013

210. Grills C, Jithesh PV, Blayney J, Zhang SD, Fennell DA (2011). Gene expression meta-analysis identifies VDAC1 as a predictor of poor outcome in early stage non-small cell lung cancer. PLoS One 6(1): e14635. doi: 10.1371/journal.pone.0014635

211. Yu H, Kim PM, Sprecher E, Trifonov V, Gerstein M (2007). The importance of bottlenecks in protein networks: correlation with gene essentiality and expression dynamics. PLoS Comput Biol 3(4): e59. doi: 10.1371/journal.pcbi.0030059

212. Prezma T, Shteinfer A, Admoni L, Raviv Z, Sela I, Levi I, ShoshanBarmatz V (2013). VDAC1-based peptides: novel pro-apoptotic agents and potential therapeutics for B-cell chronic lymphocytic leukemia. Cell death \& disease 4:e809. doi: 10.1038/cddis.2013.316

213. Shteinfer-Kuzmine A, Arif T, Krelin Y, Tripathi SS, Paul A, ShoshanBarmatz V (2017). Mitochondrial VDAC1-based peptides: Attacking oncogenic properties in glioblastoma. Oncotarget 8(19): 31329-31346. doi: 10.18632/oncotarget.15455

214. Patterson RL, van Rossum DB, Kaplin Al, Barrow RK, Snyder SH (2005). Inositol 1,4,5-trisphosphate receptor/GAPDH complex augments Ca2+ release via locally derived NADH. Proc Natl Acad Sci U S A 102(5): 1357-1359. doi: 10.1073/pnas.0409657102

215. Vyssokikh M, Zorova L, Zorov D, Heimlich G, Jurgensmeier J, Schreiner D, Brdiczka D (2004). The intra-mitochondrial cytochrome c distribution varies correlated to the formation of a complex between VDAC and the adenine nucleotide translocase: this affects Baxdependent cytochrome c release. Biochim Biophys Acta 1644(1): 2736. doi: 10.1016/j.bbamcr.2003.10.007

216. Neumann D, Buckers J, Kastrup L, Hell SW, Jakobs S (2010). Twocolor STED microscopy reveals different degrees of colocalization between hexokinase-I and the three human VDAC isoforms. PMC Biophys 3(1): 4. doi: 10.1186/1757-5036-3-4

217. Azarashvili T, Krestinina O, Baburina Y, Odinokova I, Grachev D, Papadopoulos V, Akatov V, Lemasters JJ, Reiser G (2015). Combined effect of $\mathrm{G} 3139$ and TSPO ligands on $\mathrm{Ca}(2+)$-induced permeability transition in rat brain mitochondria. Arch Biochem Biophys 587: 7077. doi: 10.1016/j.abb.2015.10.012

218. Youle RJ, Strasser A (2008). The BCL-2 protein family: opposing activities that mediate cell death. Nat Rev Mol Cell Biol 9(1): 47-59. doi: $10.1038 / \mathrm{nrm} 2308$

219. Danial NN (2007). BCL-2 family proteins: critical checkpoints of apoptotic cell death. Clin Cancer Res 13(24): 7254-7263. doi: 10.1158/1078-0432.ccr-07-1598

220. Malia TJ, Wagner G (2007). NMR structural investigation of the mitochondrial outer membrane protein VDAC and its interaction with antiapoptotic Bcl-xL. Biochemistry 46(2): 514-525. doi: 10.1021/bi061577h

221. Shimizu S, Konishi A, Kodama T, Tsujimoto Y (2000). BH4 domain of antiapoptotic Bcl-2 family members closes voltage-dependent anion channel and inhibits apoptotic mitochondrial changes and cell death. Proc Natl Acad Sci U S A 97(7): 3100-3105. doi: 10.1073/pnas.97.7.3100

222. Sugiyama T, Shimizu S, Matsuoka $Y$, Yoneda $Y$, Tsujimoto $Y$ (2002). Activation of mitochondrial voltage-dependent anion channel by apro-apoptotic BH3-only protein Bim. Oncogene 21(32): 4944 4956. doi: 10.1038/sj.onc. 1205621

223. Yamagata $H$, Shimizu S, Nishida $Y$, Watanabe $Y$, Craigen WJ, Tsujimoto $Y$ (2009). Requirement of voltage-dependent anion channel 2 for pro-apoptotic activity of Bax. Oncogene 28(40): 3563-3572. doi: 10.1038/onc. 2009.213

224. Huang H, Shah K, Bradbury NA, Li C, White C (2014). Mcl-1 promotes lung cancer cell migration by directly interacting with VDAC to increase mitochondrial $\mathrm{Ca} 2+$ uptake and reactive oxygen species generation. Cell death \& disease 5:e1482. doi: 10.1038/cddis.2014.419

225. Veenman L, Papadopoulos V, Gavish M (2007). Channel-like functions of the 18-kDa translocator protein (TSPO): regulation of apoptosis and steroidogenesis as part of the host-defense response. Curr Pharm Des 13(23): 2385-2405. doi: 10.2174/138161207781368710

226. Veenman L, Shandalov Y, Gavish M (2008). VDAC activation by the $18 \mathrm{kDa}$ translocator protein (TSPO), implications for apoptosis. J Bioenerg Biomembr 40(3): 199-205. doi: 10.1007/s10863-008-9142-1

227. Chen Y, Gaczynska M, Osmulski P, Polci R, Riley DJ (2010). Phosphorylation by Nek1 regulates opening and closing of voltage dependent anion channel 1. Biochem Biophys Res Commun 394(3): 798-803. doi: 10.1016/j.bbrc.2010.03.077

228. Zhang X, Bian X, Kong J (2014). The proapoptotic protein BNIP3 interacts with VDAC to induce mitochondrial release of endonuclease G. PLoS One 9(12): e113642. doi: 10.1371/journal.pone.0113642

229. Kusano H, Shimizu S, Koya RC, Fujita H, Kamada S, Kuzumaki N, Tsujimoto $Y$ (2000). Human gelsolin prevents apoptosis by inhibiting apoptotic mitochondrial changes via closing VDAC. Oncogene 19(42): 4807-4814. doi: 10.1038/sj.onc.1203868

230. Qiao H, McMillan JR (2007). Gelsolin segment 5 inhibits HIVinduced T-cell apoptosis via Vpr-binding to VDAC. FEBS Lett 581(3): 535-540. doi: 10.1016/j.febslet.2006.12.057

231. Carre M, Andre N, Carles G, Borghi H, Brichese L, Briand C, Braguer D (2002). Tubulin is an inherent component of mitochondrial membranes that interacts with the voltage-dependent anion channel. J Biol Chem 277(37): 33664-33669. doi: 10.1074/jbc.M203834200

232. Rostovtseva TK, Bezrukov SM (2012). VDAC inhibition by tubulin and its physiological implications. Biochim Biophys Acta 1818(6): 1526-1535. doi: 10.1016/j.bbamem.2011.11.004

233. Saks V, Guzun R, Timohhina N, Tepp K, Varikmaa M, Monge C, Beraud N, Kaambre T, Kuznetsov A, Kadaja L, Eimre M, Seppet E (2010). Structure-function relationships in feedback regulation of energy fluxes in vivo in health and disease: mitochondrial interactosome. Biochim Biophys Acta 1797(6-7): 678-697. doi: 10.1016/j.bbabio.2010.01.011

234. Roman I, Figys J, Steurs G, Zizi M (2006). Direct measurement of VDAC-actin interaction by surface plasmon resonance. Biochim Biophys Acta 1758(4): 479-486. doi: 10.1016/j.bbamem.2006.03.019 
235. Xu X, Forbes JG, Colombini M (2001). Actin modulates the gating of Neurospora crassa VDAC. J Membr Biol 180(1): 73-81. doi: $10.1007 / \mathrm{s} 002320010060$

236. Linden M, Karlsson $G$ (1996). Identification of porin as a binding site for MAP2. Biochem Biophys Res Commun 218(3): 833-836. doi: 10.1006/bbrc.1996.0148

237. Schwarzer C, Barnikol-Watanabe S, Thinnes FP, Hilschmann N (2002). Voltage-dependent anion-selective channel (VDAC) interacts with the dynein light chain Tctex1 and the heat-shock protein PBP74. Int J Biochem Cell Biol 34(9): 1059-1070. doi: 10.1016/s13572725(02)00026-2

238. Bergemalm D, Jonsson PA, Graffmo KS, Andersen PM, Brannstrom T, Rehnmark A, Marklund SL (2006). Overloading of stable and exclusion of unstable human superoxide dismutase-1 variants in mitochondria of murine amyotrophic lateral sclerosis models. The Journal of neuroscience : the official journal of the Society for Neuroscience 26(16): 4147-4154. doi: 10.1523/JNEUROSCI.5461-05.2006

239. Deng HX, Shi Y, Furukawa $Y$, Zhai H, Fu R, Liu E, Gorrie GH, Khan MS, Hung WY, Bigio EH, Lukas T, Dal Canto MC, O'Halloran TV, Siddique $T$ (2006). Conversion to the amyotrophic lateral sclerosis phenotype is associated with intermolecular linked insoluble aggregates of SOD1 in mitochondria. Proc Natl Acad Sci U S A 103(18): 7142-7147. doi: $10.1073 /$ pnas.0602046103

240. Liu J, Lillo C, Jonsson PA, Vande Velde C, Ward CM, Miller TM, Subramaniam JR, Rothstein JD, Marklund S, Andersen PM, Brannstrom T, Gredal O, Wong PC, Williams DS, Cleveland DW (2004). Toxicity of familial ALS-linked SOD1 mutants from selective recruitment to spinal mitochondria. Neuron 43(1): 5-17. doi: 10.1016/j.neuron.2004.06.016

241. Israelson A, Arbel N, Da Cruz S, Ilieva H, Yamanaka K, ShoshanBarmatz V, Cleveland DW (2010). Misfolded mutant SOD1 directly inhibits VDAC1 conductance in a mouse model of inherited ALS. Neuron 67(4): 575-587. doi: 10.1016/j.neuron.2010.07.019

242. Tan W, Naniche N, Bogush A, Pedrini S, Trotti D, Pasinelli P (2013). Small peptides against the mutant SOD1/Bcl-2 toxic mitochondrial complex restore mitochondrial function and cell viability in mutant SOD1-mediated ALS. The Journal of neuroscience : the official journal of the Society for Neuroscience 33(28): 11588-11598. PMID: 23843527

243. Sun J, Liao JK (2002). Functional interaction of endothelial nitric oxide synthase with a voltage-dependent anion channel. Proc Natl Acad Sci U S A 99(20): 13108-13113. doi: 10.1073/pnas.202260999

244. Xu LG, Wang YY, Han KJ, Li LY, Zhai Z, Shu HB (2005). VISA is an adapter protein required for virus-triggered IFN-beta signaling. Mol Cell 19(6): 727-740. doi: 10.1016/j.molcel.2005.08.014

245. Guan K, Zheng Z, Song T, He X, Xu C, Zhang Y, Ma S, Wang Y, Xu $Q$, Cao Y, Li J, Yang X, Ge X, Wei C, Zhong H (2013). MAVS regulates apoptotic cell death by decreasing K48-linked ubiquitination of voltage-dependent anion channel 1. Mol Cell Biol 33(16): 3137-3149. doi: 10.1128/MCB.00030-13

246. Viola HM, Adams AM, Davies SM, Fletcher S, Filipovska A, Hool LC (2014). Impaired functional communication between the L-type calcium channel and mitochondria contributes to metabolic inhibition in the mdx heart. Proc Natl Acad Sci U S A 111(28): E2905-2914. doi: 10.1073/pnas.1402544111
247. Mitra A, Basak T, Datta K, Naskar S, Sengupta S, Sarkar S (2013). Role of alpha-crystallin $B$ as a regulatory switch in modulating cardiomyocyte apoptosis by mitochondria or endoplasmic reticulum during cardiac hypertrophy and myocardial infarction. Cell death \& disease 4:e582. doi: 10.1038/cddis.2013.114

248. Lu L, Zhang C, Cai Q, Lu Q, Duan C, Zhu Y, Yang H (2013). Voltagedependent anion channel involved in the alpha-synuclein-induced dopaminergic neuron toxicity in rats. Acta Biochim Biophys Sin (Shanghai) 45(3): 170-178. doi: 10.1093/abbs/gms114

249. Branco AF, Pereira SL, Moreira AC, Holy J, Sardao VA, Oliveira PJ (2011). Isoproterenol cytotoxicity is dependent on the differentiation state of the cardiomyoblast H9c2 cell line. Cardiovasc Toxicol 11(3): 191 .203-doi: 10.1007/s12012-011-9111-5

250. Fulda S (2009). Tumor resistance to apoptosis. Int J Cancer 124(3): 511-515. doi: 10.1002/ijc.24064

251. Pavlova NN, Thompson CB (2016). The Emerging Hallmarks of Cancer Metabolism. Cell Metab 23(1): 27-47. doi: 10.1016/j.cmet.2015.12.006

252. Hsu PP, Sabatini DM (2008). Cancer cell metabolism: Warburg and beyond. Cell 134(5): 703-707. doi: 10.1016/j.cell.2008.08.021

253. Pedersen PL (2008). Voltage dependent anion channels (VDACs): a brief introduction with a focus on the outer mitochondrial compartment's roles together with hexokinase-2 in the "Warburg effect" in cancer. J Bioenerg Biomembr 40(3): 123-126. doi: 10.1007/s10863008-9165-7

254. Shi Y, Jiang C, Chen Q, Tang $H$ (2003). One-step on-column affinity refolding purification and functional analysis of recombinant human VDAC1. Biochem Biophys Res Commun 303(2): 475-482. doi 10.1016/s0006-291x(03)00359-0

255. Debatin KM, Poncet D, Kroemer G (2002). Chemotherapy: targeting the mitochondrial cell death pathway. Oncogene 21(57): 87868803. doi: 10.1038/sj.onc.1206039

256. Ghobrial IM, Witzig TE, Adjei AA (2005). Targeting apoptosis pathways in cancer therapy. CA Cancer J Clin 55(3): 178-194. doi: 10.3322/canjclin.55.3.178

257. Hu W, Kavanagh JJ (2003). Anticancer therapy targeting the apoptotic pathway. Lancet Oncol 4(12): 721-729. doi: 10.1016/S14702045(03)01277-4

258. Kaufmann SH, Vaux DL (2003). Alterations in the apoptotic machinery and their potential role in anticancer drug resistance. Oncogene 22(47): 7414-7430. doi: 10.1038/sj.onc.1206945

259. Kim R, Emi M, Tanabe K, Uchida Y, Arihiro K (2006). The role of apoptotic or nonapoptotic cell death in determining cellular response to anticancer treatment. Eur J Surg Oncol 32(3): 269-77. doi: 10.1016/j.ejso.2005.12.006

260. Hail N, Jr. (2005). Mitochondria: A novel target for the chemoprevention of cancer. Apoptosis 10(4): 687-705. doi: 10.1007/s10495005-0792-8

261. Gallego MA, Joseph B, Hemstrom TH, Tamiji S, Mortier L, Kroemer G, Formstecher P, Zhivotovsky B, Marchetti P (2004). Apoptosisinducing factor determines the chemoresistance of non-small-cell lung carcinomas. Oncogene 23(37): 6282-6291. doi: 10.1038/sj.onc. 1207835 
262. Debatin KM (1999). Activation of apoptosis pathways by anticancer drugs. Advances in experimental medicine and biology 457:237-244. doi: 10.1007/978-1-4615-4811-9_25

263. Preston TJ, Abadi A, Wilson L, Singh G (2001). Mitochondrial contributions to cancer cell physiology: potential for drug development. Advanced drug delivery reviews 49(1-2): 45-61. doi: 10.1016/S0169-409X(01)00127-2

264. Costantini P, Jacotot E, Decaudin D, Kroemer G (2000). Mitochondrion as a novel target of anticancer chemotherapy. J Natl Cancer Inst 92(13): 1042-1053. doi: 10.1093/jnci/92.13.1042

265. Gogvadze V, Orrenius S, Zhivotovsky B (2009). Mitochondria as targets for chemotherapy. Apoptosis. doi: 10.1016/j.semcancer.2008.11.007

266. Visvader Jane E, Lindeman Geoffrey J (2012). Cancer Stem Cells: Current Status and Evolving Complexities. Cell Stem Cell 10(6): 717728. doi: 10.1016/j.stem.2012.05.007

267. Chen J, Li Y, Yu T-S, McKay RM, Burns DK, Kernie SG, Parada LF (2012). A restricted cell population propagates glioblastoma growth after chemotherapy. Nature 488(7412): 522-526. doi: $10.1038 /$ nature 11287

268. Valent $P$, Bonnet D, De Maria R, Lapidot T, Copland M, Melo JV, Chomienne C, Ishikawa F, Schuringa JJ, Stassi G, Huntly B, Herrmann $H$, Soulier J, Roesch A, Schuurhuis GJ, Wohrer S, Arock M, Zuber J, Cerny-Reiterer S, Johnsen HE, Andreeff M, Eaves C (2012). Cancer stem cell definitions and terminology: the devil is in the details. Nat Rev Cancer 12(11): 767-75. doi: 10.1038/nrc3368

269. Lee JT, Herlyn M (2007). Old disease, new culprit: Tumor stem cells in cancer. Journal of Cellular Physiology 213(3): 603-609. doi: 10.1002/jcp. 21252

270. Frank NY, Schatton T, Frank MH (2010). The therapeutic promise of the cancer stem cell concept. The Journal of Clinical Investigation 120(1): 41-50. doi: $10.1172 / \mathrm{JCl} 41004$

271. Zhang G, Jiang G, Wang C, Zhong K, Zhang J, Xue Q, Li X, Jin H, Li B (2016). Decreased expression of microRNA-320a promotes proliferation and invasion of non-small cell lung cancer cells by increasing VDAC1 expression. Oncotarget 7(31): 49470-49480. doi: 10.18632/oncotarget.9943

272. Lezi E, Swerdlow RH (2012). Mitochondria in neurodegeneration. Advances in experimental medicine and biology 942:269-286. doi: 10.1007/978-94-007-2869-1_12

273. Mattson MP, Gleichmann M, Cheng A (2008). Mitochondria in neuroplasticity and neurological disorders. Neuron 60(5): 748-766. doi: 10.1016/j.neuron.2008.10.010

274. Manczak M, Park BS, Jung Y, Reddy PH (2004). Differential expression of oxidative phosphorylation genes in patients with Alzheimer's disease: implications for early mitochondrial dysfunction and oxidative damage. Neuromolecular Med 5(2): 147-162. doi: 10.1385/NMM:5:2:147

275. Benek O, Aitken L, Hroch L, Kuca K, Gunn-Moore F, Musilek K (2015). A Direct interaction between mitochondrial proteins and amyloid-beta peptide and its significance for the progression and treatment of Alzheimer's disease. Curr Med Chem. doi: $10.2174 / 0929867322666150114163051$
276. Devi L, Ohno M (2012). Mitochondrial dysfunction and accumulation of the beta-secretase-cleaved C-terminal fragment of APP in Alzheimer's disease transgenic mice. Neurobiology of disease $45(1)$ : 417-424 .doi: 10.1016/j.nbd.2011.09.001

277. Petrozzi L, Ricci G, Giglioli NJ, Siciliano G, Mancuso M (2007) Mitochondria and neurodegeneration. Biosci Rep 27(1-3): 87-104. doi: 10.1007/s10540-007-9038-z

278. Radi E, Formichi P, Battisti C, Federico A (2014). Apoptosis and oxidative stress in neurodegenerative diseases. JAD 42 (Suppl 3): S125-152. PMID: 25056458

279. Gervais FG, Xu D, Robertson GS, Vaillancourt JP, Zhu Y, Huang J, LeBlanc A, Smith D, Rigby $M$, Shearman MS, Clarke EE, Zheng $H$, Van Der Ploeg LH, Ruffolo SC, Thornberry NA, Xanthoudakis S, Zamboni RJ, Roy S, Nicholson DW (1999). Involvement of caspases in proteolytic cleavage of Alzheimer's amyloid-beta precursor protein and amyloidogenic A beta peptide formation. Cell 97(3): 395-406. doi: 10.1016/s0092-8674(00)80748-5

280. Li M, Ona VO, Guegan C, Chen M, Jackson-Lewis V, Andrews L, Olszewski AJ, Stieg PE, Lee JP, Przedborski S, Friedlander RM (2000). Functional role of caspase-1 and caspase- 3 in an ALS transgenic mouse model. Science 288(5464): 335-339. doi: $10.1126 /$ science.288.5464.335

281. Friedlander RM (2003). Apoptosis and caspases in neurodegenerative diseases. N Engl J Med 348(14): 1365-1375. doi: 10.1056/NEJMra022366

282. Hirai K, Aliev G, Nunomura A, Fujioka H, Russell RL, Atwood CS, Johnson $A B$, Kress $Y$, Vinters HV, Tabaton $M$, Shimohama $S$, Cash AD, Siedlak SL, Harris PL, Jones PK, Petersen RB, Perry G, Smith MA (2001). Mitochondrial abnormalities in Alzheimer's disease. The Journal of neuroscience : the official journal of the Society for Neuroscience 21(9): 3017-3023. PMID: 11312286

283. Aleardi AM, Benard G, Augereau O, Malgat M, Talbot JC, Mazat JP, Letellier T, Dachary-Prigent J, Solaini GC, Rossignol R (2005). Gradual alteration of mitochondrial structure and function by betaamyloids: importance of membrane viscosity changes, energy deprivation, reactive oxygen species production, and cytochrome $c$ release. $J$ Bioenerg Biomembr 37(4): 207-225. doi: 10.1007/s10863-005-6631-3

284. Ferrer I (2009) .Altered mitochondria, energy metabolism, voltage-dependent anion channel, and lipid rafts converge to exhaust neurons in Alzheimer's disease. J Bioenerg Biomembr 41(5): 425-431. doi: 10.1007/s10863-009-9243-5

285. Ramirez CM, Gonzalez M, Diaz M, Alonso R, Ferrer I, Santpere G, Puig B, Meyer G, Marin R (2009). VDAC and ERalpha interaction in caveolae from human cortex is altered in Alzheimer's disease. Mol Cell Neurosci 42(3): 172-183. doi: 10.1016/j.mcn.2009.07.001

286. Reddy PH (2013). Is the mitochondrial outermembrane protein VDAC1 therapeutic target for Alzheimer's disease? Biochim Biophys Acta 1832(1): 67-75. doi: 10.1016/j.bbadis.2012.09.003

287. Yoo BC, Fountoulakis M, Cairns N, Lubec G (2001). Changes of voltage-dependent anion-selective channel proteins VDAC1 and VDAC2 brain levels in patients with Alzheimer's disease and Down syndrome. Electrophoresis 22(1): 172-179. doi: 10.1002/15222683(200101)22:1<172::AID-ELPS172>3.0.CO;2-P 
288. Fukada K, Zhang F, Vien A, Cashman NR, Zhu H (2004). Mitochondrial proteomic analysis of a cell line model of familial amyotrophic lateral sclerosis. Mol Cell Proteomics 3(12): 1211-1223. doi: 10.1074/mcp.M400094-MCP200

289. Marin R, Ramirez CM, Gonzalez M, Gonzalez-Munoz E, Zorzano A, Camps M, Alonso R, Diaz M (2007). Voltage-dependent anion channel (VDAC) participates in amyloid beta-induced toxicity and interacts with plasma membrane estrogen receptor alpha in septal and hippocampal neurons. Mol Membr Biol 24(2): 148-160. doi: 10.1080/09687860601055559

290. Reddy PH (2013). Amyloid beta-induced glycogen synthase kinase 3beta phosphorylated VDAC1 in Alzheimer's disease: implications for synaptic dysfunction and neuronal damage. Biochim Biophys Acta 1832(12): 1913-1921. doi: 10.1016/j.bbadis.2013.06.012

291. Smilansky A, Dangoor L, Nakdimon I, Ben-Hail D, Mizrachi D, Shoshan-Barmatz V (2015). The Voltage-dependent Anion Channel 1 Mediates Amyloid beta Toxicity and Represents a Potential Target for Alzheimer Disease Therapy. J Biol Chem 290(52): 30670-30683. doi: 10.1074/jbc.M115.691493

292. Jiang W, Du B, Chi Z, Ma L, Wang S, Zhang X, Wu W, Wang X, Xu $G$, Guo C (2007). Preliminary explorations of the role of mitochondrial proteins in refractory epilepsy: some findings from comparative proteomics. J Neurosci Res 85(14): 3160-3170. doi: 10.1002/jnr.21384

293. Sultana R, Poon HF, Cai J, Pierce WM, Merchant M, Klein JB, Markesbery WR, Butterfield DA (2006). Identification of nitrated proteins in Alzheimer's disease brain using a redox proteomics approach. Neurobiology of disease 22(1): 76-87. doi: 10.1016/j.nbd.2005.10.004

294. Roshan R, Shridhar S, Sarangdhar MA, Banik A, Chawla M, Garg $M$, Singh VP, Pillai $B$ (2014). Brain-specific knockdown of miR-29 results in neuronal cell death and ataxia in mice. RNA 20(8): 1287-1297. doi: $10.1261 /$ rna.044008.113

295. Stary CM, Sun X, Ouyang Y, Li L, Giffard RG (2016). miR-29a differentially regulates cell survival in astrocytes from cornu ammonis 1 and dentate gyrus by targeting VDAC1. Mitochondrion 30:248-254. doi: 10.1016/j.mito.2016.08.013

296. Fatima M, Prajapati B, Saleem K, Kumari R, Mohindar Singh Singal C, Seth P (.(2017Novel insights into role of miR-320a-VDAC1 axis in astrocyte-mediated neuronal damage in neuroAIDS. Glia 65(2): 250263. doi: 10.1002/glia.23089

297. Zimmet P, Alberti KG, Shaw J (2001). Global and societal implications of the diabetes epidemic. Nature 414(6865): 782-787. doi: $10.1038 / 414782 a$

298. Bolen S, Feldman L, Vassy J, Wilson L, Yeh HC, Marinopoulos S, Wiley C, Selvin E, Wilson R, Bass EB, Brancati FL (2007). Systematic review: comparative effectiveness and safety of oral medications for type 2 diabetes mellitus. Ann Intern Med 147(6): 386-399. doi: 10.7326/0003-4819-147-6-200709180-00178

299. Sasaki K, Donthamsetty R, Heldak M, Cho YE, Scott BT, Makino A (2012). VDAC: old protein with new roles in diabetes. Am J Physiol Cell Physiol 303(10): C1055-1060. doi: 10.1152/ajpcell.00087.2012
300. Truong AH, Murugesan KD, Youssef A, Makino (2016). Mitochondrial Ion Channels in Metabolic Disease,. Springer International Publishing, Place Published, in: P.I. Levitan, M.D.P.M.A. Dopico (Eds.) Vascular Ion Channels in Physiology and Disease, pp. 397-419. doi: 10.1007/978-3-319-29635-7_18

301. Lowell BB, Shulman GI (2005). Mitochondrial dysfunction and type 2 diabetes. Science 307(5708): 384-387. doi: 10.1126/science. 1104343

302. Jiang X, Wang X (2000). Cytochrome c promotes caspase-9 activation by inducing nucleotide binding to Apaf-1. J Biol Chem 275(40): 31199-31203. doi: 10.1074/jbc.C000405200

303. Hay N (2016). Reprogramming glucose metabolism in cancer: can it be exploited for cancer therapy? Nat Rev Cancer 16(10): 635-49. doi: $10.1038 /$ nrc. 2016.77

304. Johnstone RW, Ruefli AA, Lowe SW (2002). Apoptosis: a link between cancer genetics and chemotherapy. Cell 108(2): 153-164. PMID: 11832206

305. Takehara T, Liu X, Fujimoto J, Friedman SL, Takahashi H (2001). Expression and role of $\mathrm{Bcl}-\mathrm{xL}$ in human hepatocellular carcinomas. Hepatology 34(1): 55-61. doi: 10.1053/jhep.2001.25387

306. Ding Z, Yang X, Pater A, Tang SC (2000) . Resistance to apoptosis is correlated with the reduced caspase- 3 activation and enhanced expression of antiapoptotic proteins in human cervical multidrugresistant cells. Biochem Biophys Res Commun 270(2): 415-420. doi: 10.1006/bbrc. 2000.2432

307. Grobholz R, Zentgraf H, Kohrmann KU, Bleyl U (2002). Bax, Bcl-2, fas and Fas-L antigen expression in human seminoma: correlation with the apoptotic index. Apmis 110(10): 724-732. doi: 10.1034/j.16000463.2002.1101006.x

308. Krajewska M, Moss SF, Krajewski S, Song K, Holt PR, Reed JC (1996). Elevated expression of Bcl-X and reduced Bak in primary colorectal adenocarcinomas. Cancer Res 56(10): 2422-2427. PMID: 8625322

309. Pedersen PL (2007). Warburg, me and Hexokinase 2: Multiple discoveries of key molecular events underlying one of cancers' most common phenotypes, the "Warburg Effect", i.e., elevated glycolysis in the presence of oxygen. J Bioenerg Biomembr 39(3): 211-222. doi: 10.1007/s10863-007-9094-x

310. Mathupala SP, Ko YH, Pedersen PL (2009). Hexokinase-2 bound to mitochondria: cancer's stygian link to the "Warburg Effect" and a pivotal target for effective therapy. Semin Cancer Biol 19(1): 17-24. doi: 10.1016/j.semcancer.2008.11.006

311. Shimizu S, Ide T, Yanagida T, Tsujimoto Y (2000). Electrophysiological study of a novel large pore formed by Bax and the voltagedependent anion channel that is permeable to cytochrome c. J Biol Chem 275(16): 12321-12325. doi: 10.1074/jbc.275.16.12321

312. Pastorino JG, Shulga N, Hoek JB (2002). Mitochondrial binding of hexokinase II inhibits Bax-induced cytochrome c release and apoptosis. J Biol Chem 277(9): 7610-7618. doi: 10.1074/jbc.M109950200 